\title{
$\frac{0}{24} \cdot 92853$
}

\section{PERFORMANCE OF MHD INSULATING MATERIALS IN A POTASSIUM ENVIRONMENT}

by

\author{
K. Natesan, J. H. Park, \\ D. L. Rink, and C. A. Thomas
}

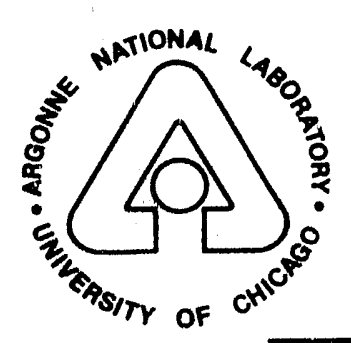

ARGONNE NATIONAL LABORATORY, ARGONNE, ILLINOIS

Operated by THE UNIVERSITY OF CHICAGO for the U.S. DEPARTMENT OF ENERGY

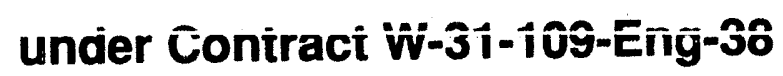


Argonne National Laboratory, with facilities in the states of Illinois and Idaho, is owned by the United States government, and operated by The University of Chicago under the provisions of a contract with the Department of Energy.

\section{DISCLAIMER}

This report was prepared as an account of work sponsored by an agency of the United States Government. Neither the United States Government nor any agency thereof, nor any of their employees, makes any warranty, express or implied, or assumes any legal liability or responsibility for the accuracy, completeness, or usefulness of any information, apparatus, product, or process disclosed, or represents that its use vould not infringe privately owned rights. Reference herein to any specific commercial product, process, or service by trade name, tradernark, manufacturer, or otherwise, does not necessarily constitute or imply its endorsement, recommendation, or favoring by the United States Government or any agency thereof. The views and opinions of authors expressed herein do not necessarily state or reflect those of the United States Government or any agency thereof.

Reproduced from the best available copy.

Available to DOE and DOE contractors from the Office of Scientific and Technical Information

P.O. Box 62

Oak Ridge, TN 37831

Prices available from (615) 576-8401, FTS 626-8401

Available to the public from the National Technical Information Service

U.S. Department of Commerce 5285 Port Royal Road Springfield, VA 22161 


\title{
ARGONNE NATIONAL LABORATORY \\ 9700 South Cass Avenue \\ Argonne, Illinois 60439
}

\author{
ANL/MHD-91/1 \\ PERformance of MID INSULATING Materials IN A \\ POTASSIUM ENVIRONMENT \\ by \\ K. Natesan, J. H. Park, D. L. Rink, and C. A. Thomas* \\ Materials and Components Technology Division
}

December 1991

Work supported by

U.S. DEPARTMENT OF ENERGY

Pittsburgh Energy Technology Center

*Pittsburgh Energy Technology Center 


\section{CONTENTS}

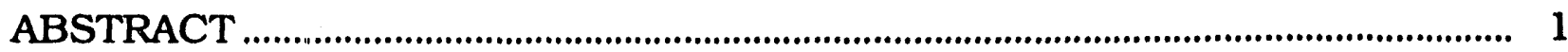

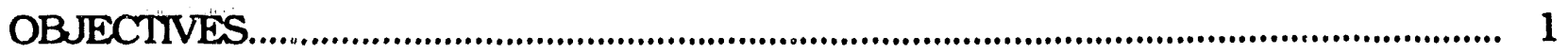

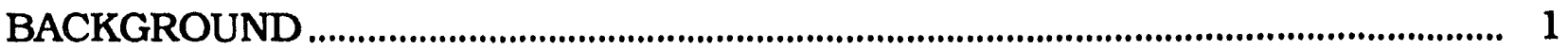

TEST PROCEDURE ................................................................................................ 4

Chemical Compatibility .................................................................................. 5

Electrical Conductivity.................................................................................... 7

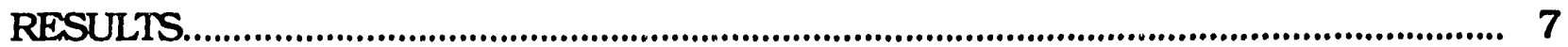

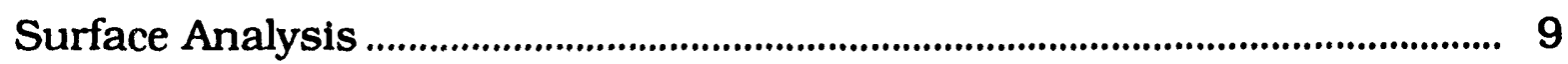

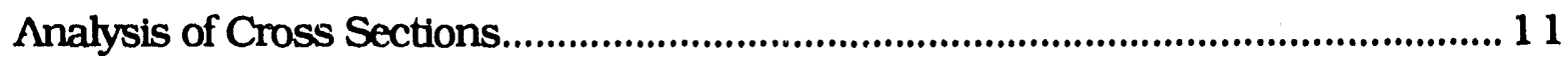

Electrical Conductivity Data............................................................................ 19

IMPLICATIONS FOR MHD CHANNEL DESIGN.....................................................2 21

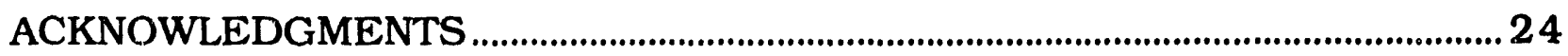

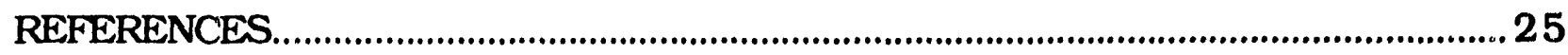




\section{FIGURES}

1. Cross sections of $1 \mathrm{~A}_{1}$ workhorse channel anode and cathode.............. 2

2. A $_{1}$ channel cathode-to-sidewall joint using boron nitride..................... 3

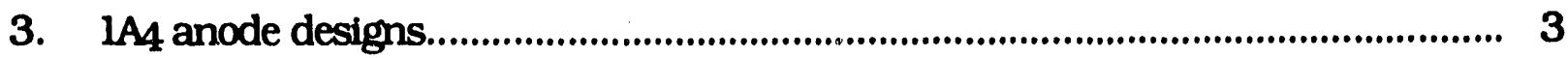

4. 1 A4 cathode design.................................................................................................... 4

5. Schematic representation of channel wall in an MHD system................ 5

6. Schematic diagram of specimens and capsule assembly for potassium exposure............................................................................................................... 6

7. Schematic diagram of setup used to measure electrical conductivity.

8. SEM micrographs of boron nitride and silicon nitride samples before exposure to potassium ............................................................................... 8

9. Macroscopic view of potassium-exposed specimens..................................... 9

10. SEM micrographs of boron nitride specimen after exposure at $1400^{\circ} \mathrm{F}$ in potassium vapor........................................................................................... 10

11. SEM micrographs of boron nitride specimen after exposure at $1400^{\circ} \mathrm{F}$ in potassium liquid ........................................................................................ 11

12. SEM micrographs of boron nitride specimen after exposure at $1000^{\circ} \mathrm{F}$ in potassium vapor.

13. SEM micrographs of boron nitride specimen after exposure at $1000^{\circ} \mathrm{F}$ in potassium liquid.

14. SEM micrographs of ANL-archive boron nitride specimen after exposure at $1000^{\circ} \mathrm{F}$ in potassium liquid

15. SEM micrographs of silicon nitride specimens after exposure at $1400^{\circ} \mathrm{F}$ in potassium vapor and liquid

16. SEM micrographs of silicon nitride specimens after exposure at $1000^{\circ} \mathrm{F}$ in potassium vapor and liquid 
17. SEM micrograph and potassium mapping of cross section of boron nitride specimen after exposure at $1000^{\circ} \mathrm{F}$ in potassium vapor.

18. SEM micrograph and potassium mapping of cross section of boron nitride specimen after exposure at $1000^{\circ} \mathrm{F}$ in potassium liquid

19. SEM micrograph and potassium mapping of cross section of boron nitride specimen after exposure at $1400^{\circ} \mathrm{F}$ in potassium vapor.

20. SEM micrograph of cross section of silicon nitride specimen after exposure at $1400^{\circ} \mathrm{F}$ in potassium vapor

21. Electrical conductivity as a function of temperature in boron nitride before and after exposure to potassium vapor or liquid at $1400^{\circ} \mathrm{F}$

22. Electrical conductivity as a function of temperature in boron nitride before and after exposure to potassium vapor or liquid at $1000^{\circ} \mathrm{F}$

23. Electrical conductivity as a function of temperature in silicon nitride before and after exposure to potassium vapor or liquid at $1400^{\circ} \mathrm{F}$

24. Electrical conductivity as a function of temperature in silicon nitride before and after exposure to potassium vapor or liquid at $1000^{\circ} \mathrm{F}$

\section{TABLES}

1. Physical and mechanical properties of boron nitride and silicon nitride 


\title{
PERFORMANCE OF MHD INSULATING MATERIALS \\ IN A POTASSIUM ENVIRONMENT
}

\author{
K. Natesan, J. H. Park, D. L. Rink, and C. A. Thomas*
}

\begin{abstract}
Experiments were conducted to evaluate the compatibility of the MHD insulating materials boron nitride and silicon nitride in liquid and vapor potassium environments. Detailed microscopic examination of the exposed specimens showed substantial penetration of potassium in boron nitride samples, while the silicon nitride material was almost unaffected. Electrical conductivity measurements of the exposed specimens showed 5 to 6 orders of magnitude increase in conductivity of boron nitride, while a maximum of 1 -order increase was observed in silicon nitride.
\end{abstract}

\section{OBJECTIVES}

The objectives of this study are to evaluate the compatibility of the MHD insulating materials boron nitride and silicon nitride in a potassium environment at temperatures of 1000 and $1400^{\circ} \mathrm{F}\left(538\right.$ and $760^{\circ} \mathrm{C}$, respectively) and to measure the electrical conductivities of the specimens before and after exposure to potassium. Based on the test results, an assessment is to be made of the suitability of these materials for application as insulator materials in an MHD channel.

\section{BACKGROUND}

The life of an MHD channel is determined chiefly by the design and material selection of the internal wall elements--electrodes, sidebars, and insulators-which are collectively called the gas-side design. Adequate performance of materials selected for the MHD channel construction is mandatory for successful application of this technology in retrofit and commercial coal-fired energy systems. In the high-temperature environment of the MHD channel, vaporization of several coal/seed components and subsequent deposition of these materials on the walls of the channel can occur. This hostile environment, in general, contains potassium compounds, sulfur compounds, and ash/slag constituents.

\footnotetext{
"Pittsburgh Energy Technology Center.
} 
The MHD channel design has evolved over the years. The early workhorse channel had a design life of $100 \mathrm{~h}$ and was used to study the channel performance as function of various operating conditions. In the $1 A_{1}$ workhorse channel electrode and sidewall elements, a water-cooled copper-base element capped with either Type 446 stainless steel or $75 \mathrm{~W}-$ $25 \mathrm{Cu}$ alloy was used to extend element life. 1 Cross sections of the anode and cathode wall elements are shown in Fig. 1. All gas-side surfaces were grooved to promote slag retention. A boron nitride ceramic insulator was used at the corner joint of the sidewall and cathode wall, as shown in Fig. 2.

The 1A4 channel is the first MHD channel subjected to prototypical long-term operation with coal as a feedstock. 2 This channel is a major component in a 1000-h MHD Integrated Topping Cycle Proof-of-Concept test to be conducted at the Component Development and Integration Facility (CDIF) in Butte, Montana. Design of this channel was based on the 1Al experience and the proof-of-concept (POC) program requirements. The anode and cathode designs in this channel also utilize boron nitride as an insulating material, as shown in Figs. 3 and 4.

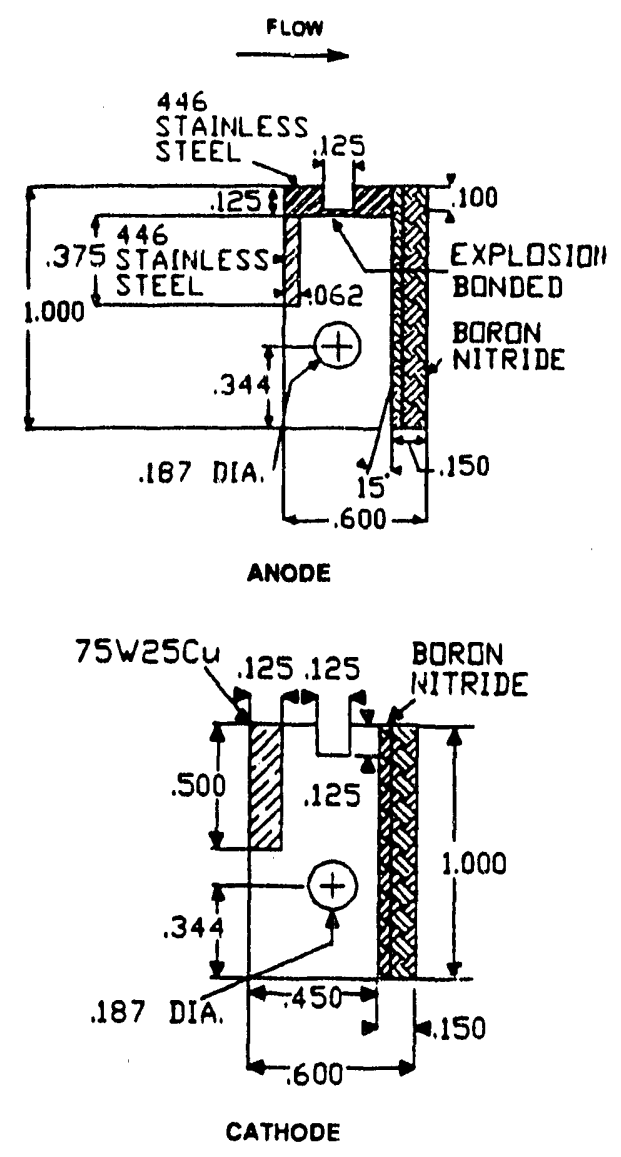

Fig. 1.

Cross sections of $1 A_{1}$ workhorse channel anode and cathode 


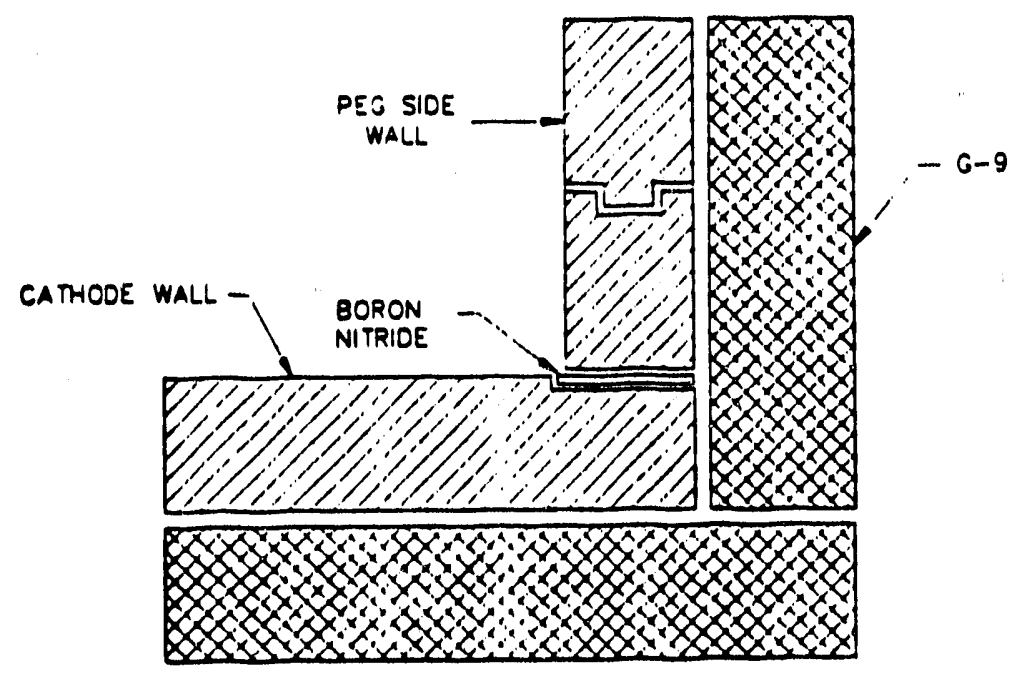

Fig. 2. 1A 1 channel cathode-to-sidewall joint using boron nitride

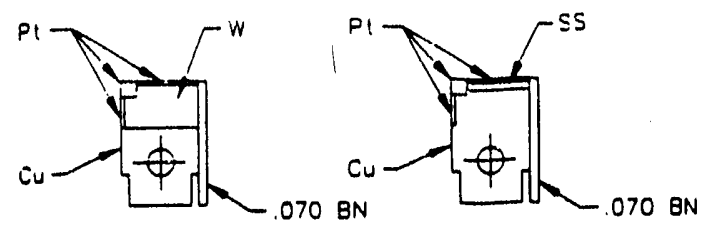

FORWARO RECIONS

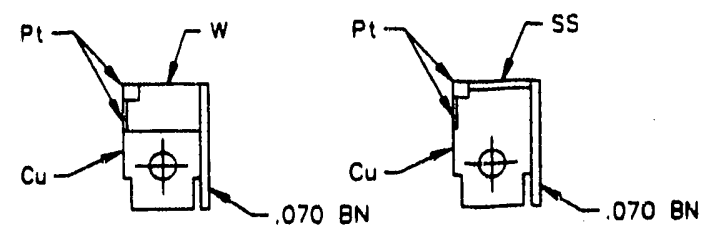

REAR REGIONS

SYMBOLS

PI - PLATINUM

W- TUNCSTEN

SS-. 446 STAINLESS STEEL

$\mathrm{CU}$ - OFHC COPPER

BN- BORON NITRIDE

CAP DIMENSIONS

W- .375 THK

Pt- .030 THK \& 125 SO

SS- .060 THK

CAP ATTACHMENTS

PI TO $W$

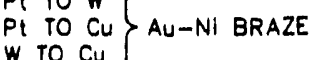

$\left.\begin{array}{lll}P t & \text { TO } & \text { SS } \\ \text { SS } & \text { TO } & \mathrm{Cu}\end{array}\right\}$ EXPLOSION BOND

Fig. 3. 1A4 anode designs 


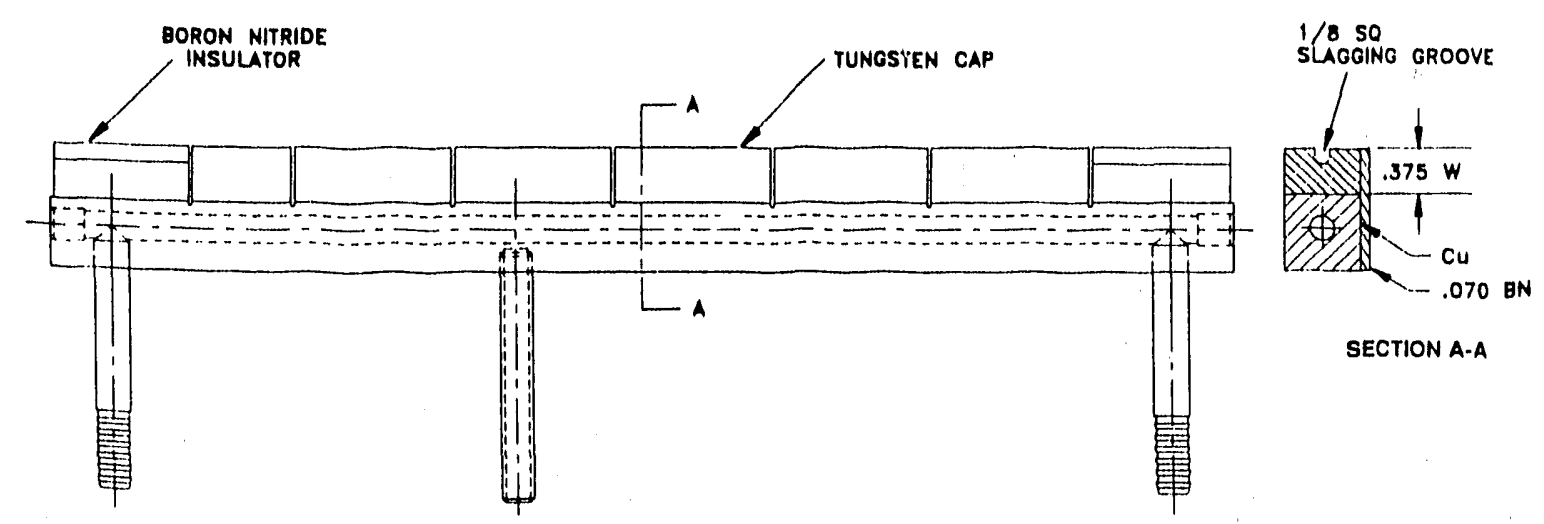

Fig. 4. 1A4 cathode design

A concern in the gas-side design of the channel is the integrity of the insulating material that separates the cathode segments. The gas side can be coated with a deposit of molten potassium and slag constituents. At any given temperature, the vapor pressures of the potassium compounds are generally much higher than those of the slag constituents; therefore, positively charged potassium ions will migrate toward the cathode, condense first on the channel wall, and be in contact with the electrode and the insulator materials. Figure 5 schematically represents the channel wall and the deposit layers anticipated during operation. Anticipated thickness of the deposit layer is $2-3 \mathrm{~mm}$ and the expected temperature range is $1000-1500^{\circ} \mathrm{F}\left(538-816^{\circ} \mathrm{C}\right)$. Under these conditions, if potassium migrated into the boron nitride and degraded its insulating properties, shorting and/or arcing between the electrodes can occur and affect the channel performance.

This study was conducted to examine the compatibility of the boron nitride material in liquid potassium and also to evaluate an alternate material (silicon nitride) exposed to the same environment. Furthermore, changes in electrical conductivities were measured for these two materials before and after exposure to the potassium environment.

\section{TEST PROCEDURE}

Two types of data were developed for the boron nitride and silicon nitride materials: (1) corrosion compatibility in potassium liquid and vapor and (2) measurement of electrical conductivity before and after exposure to potassium. 


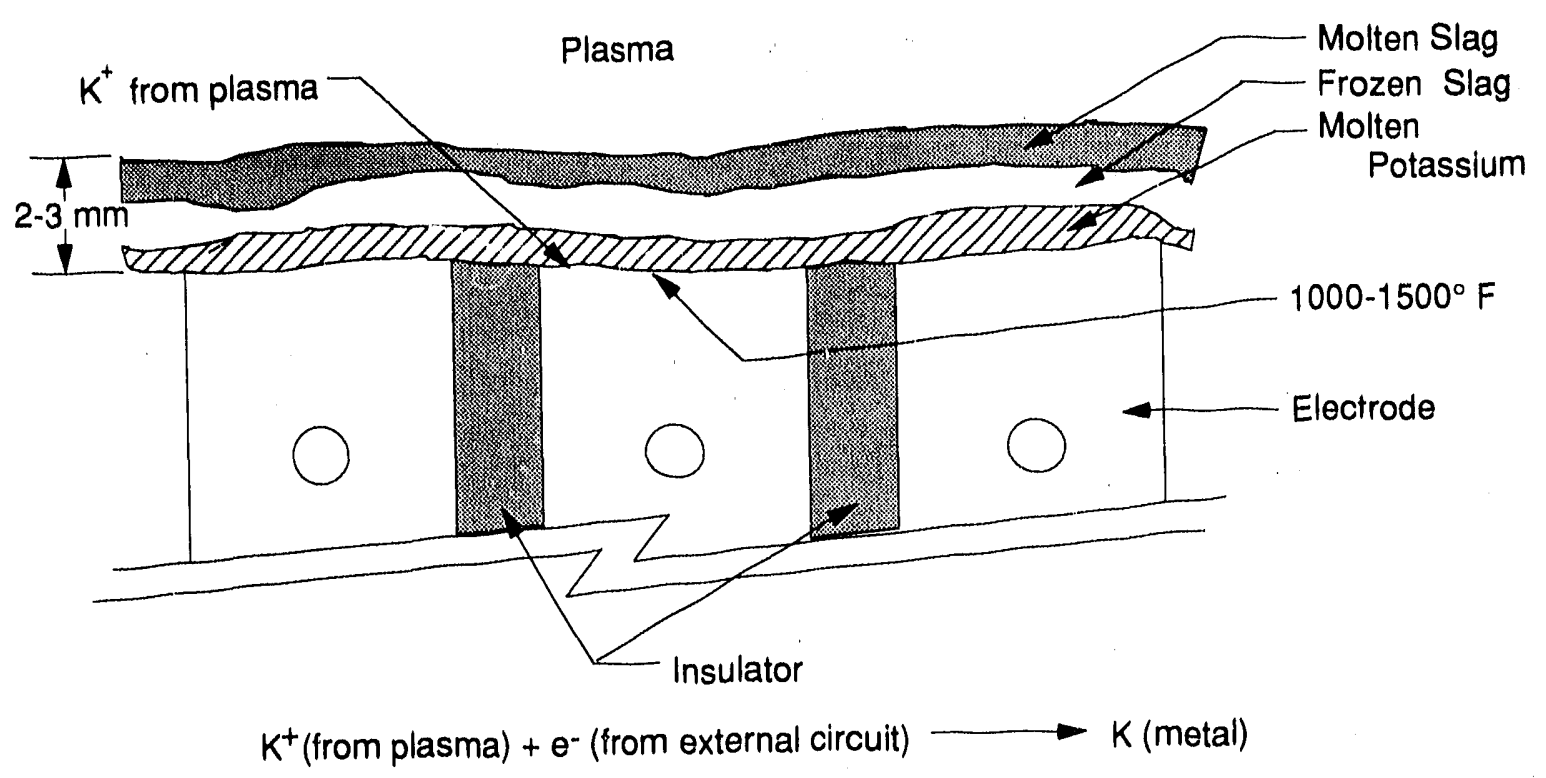

Fig. 5. Schematic representation of channel wall in an MHD system

Sheet samples of boron nitride and block samples of silicon nitride were obtained from the Pittsburgh Energy Technology Center. The boron nitride samples were designated as hexagonal BN Grade H.P.and produced by Carborundum, Niagara Falls, NY. Most of the samples were $\approx 75 \times 25 \times$ $1 \mathrm{~mm}$ in size, while a few pieces were $2.5 \mathrm{~mm}$ thick. In addition, a few archive pieces of boron nitride from Argonne National Laboratory (ANL) stock were included for evaluation. In addition, silicon nitride samples termed NORALIDE NC-132 and manufactured by Norton Company were included for evaluation. These samples were $25 \times 32 \times 6.3 \mathrm{~mm}$. Table 1 lists the physical and mechanical properties of the two materials.

\section{Chemical Compatibility}

Testing of chemical compatibility was at temperatures of 1000 and $1400^{\circ} \mathrm{F}\left(538\right.$ and $760^{\circ} \mathrm{C}$ ) and for times of up to $250 \mathrm{~h}$. Capsules were fabricated from Type 304 stainless steel, and solid potassium was inserted into the capsules so that half the internal volume of each capsule would be occupied by liquid potassium at elevated temperatures. Samples of boron nitride and silicon nitride were inserted into the capsules, and baffles were used to isolate the set of specimens for vapor-phase exposure from the set for liquid potassium immersion (see Fig. 6). The capsules were evacuated with a mechanical pump, backfilled with a partial pressure of argon gas, and welded shut; they were then exposed in resistance-wound furnaces at 1000 and $1400^{\circ} \mathrm{F}$. The vapor pressure of potassium at 1000 and $1400^{\circ} \mathrm{F}$ is 0.07 and $\approx 1.0 \mathrm{~atm}$, respectively. 
Table 1. Physical and mechanical properties of boron nitride and silicon nitride

\begin{tabular}{lcc}
\hline \multicolumn{1}{c}{ Properties } & $\begin{array}{c}\text { Boron } \\
\text { Nitride }\end{array}$ & $\begin{array}{c}\text { Silicon } \\
\text { Nitride }\end{array}$ \\
\hline Flexural Strength at $\approx 20^{\circ} \mathrm{C}(\mathrm{MPa})$ & 110 & 990 \\
Compressive Strength at $20^{\circ} \mathrm{C}(\mathrm{GPa})$ & 0.12 & 3.0 \\
Fracture Toughness, $\mathrm{KIC}\left(\mathrm{MPa} . \mathrm{m}^{0.5}\right)$ & - & 5.4 \\
Young's Modulus $(\mathrm{GPa})$ & 68 & 310 \\
Poisson's Ratio & - & 0.28 \\
Density (g/cm 3 ) & 2.2 & 3.2 \\
Hardness, $\mathrm{KHN} 100\left(\mathrm{~kg} / \mathrm{mm}^{2}\right)$ & 205 & 2000 \\
Thermal Expansion $\left({ }^{\circ} \mathrm{C}-1\right)$ & $3.2 \times 10^{-6}$ & $3.5 \times 10^{-6}$ \\
Thermal Conductivity $\left(\mathrm{W} / \mathrm{m} \mathrm{K}^{\mathrm{K}}\right)$ & 55 & 32 \\
Maximum Use Temperature $\left({ }^{\circ} \mathrm{C}\right) \mathrm{a}$ & 850 & 1300 \\
Critical Quench $\Delta \mathrm{T}\left({ }^{\circ} \mathrm{C}\right)$ & - & 600 \\
\hline
\end{tabular}

aln oxddizing environments.

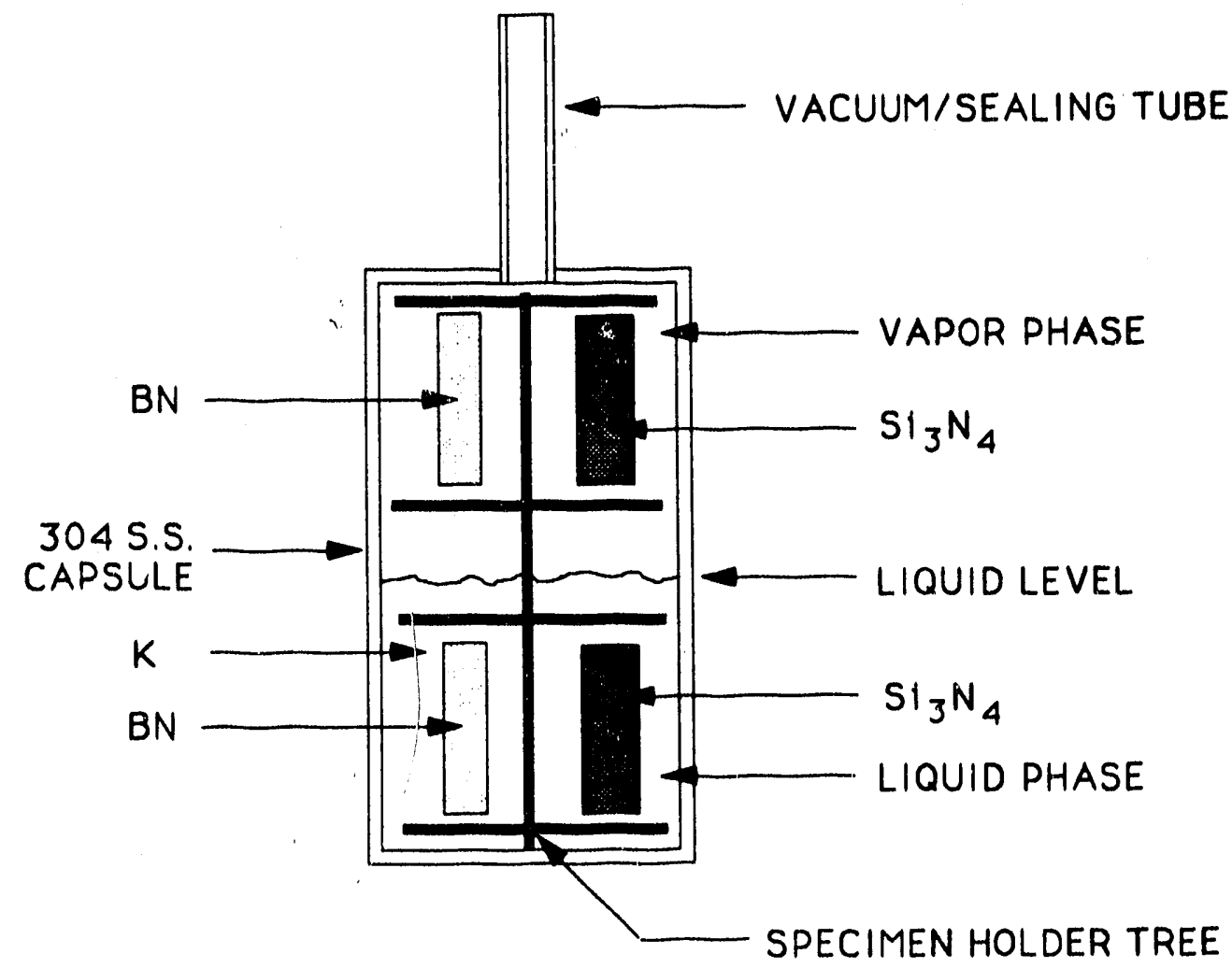

Fig. 6. Schematic diagram of specimens and capsule assembly for potassium exposure 


\section{Electrical Conductivity}

Measurements of electrical conductivity measurements were made by a two-probe method using a conductivity cell constructed at ANL. The cell, schematically shown in Fig. 7, consisted of an alumina chamber in which a sample of either boron nitride or silicon nitride was inserted with lead wires of gold attached. The temperature measurements were made with a Chromel-Alumel thermocouple. The portion of the cell ccntaining the specimen was inserted in a resistance furnace. The alumina chamber was sealed with a Teflon cap outside the furnace and the chamber had a flow of highpurity (99.999 vol.\%) argon gas during the conductivity measurements. Measurements were made on both boron nitride and silicon nitride materials before and after exposure to potassium vapor and liquid at 1000 and $1400^{\circ} \mathrm{F}$.

\section{RESULTS}

Detailed microstructural analyses of the exnosed specimens were conducted with a scanning electron microscope (SEM). Figure 8 shows SEM miciographs of surfaces of boron nitride and silicon nitride specimens before exposure in the potassium-containing capsules. The boron nitride specimens seemed more porous than the silicon nitride specimens. The boron nitride specimens, being mechanically weak, were more susceptible to cracking than the silicon nitride specimens.

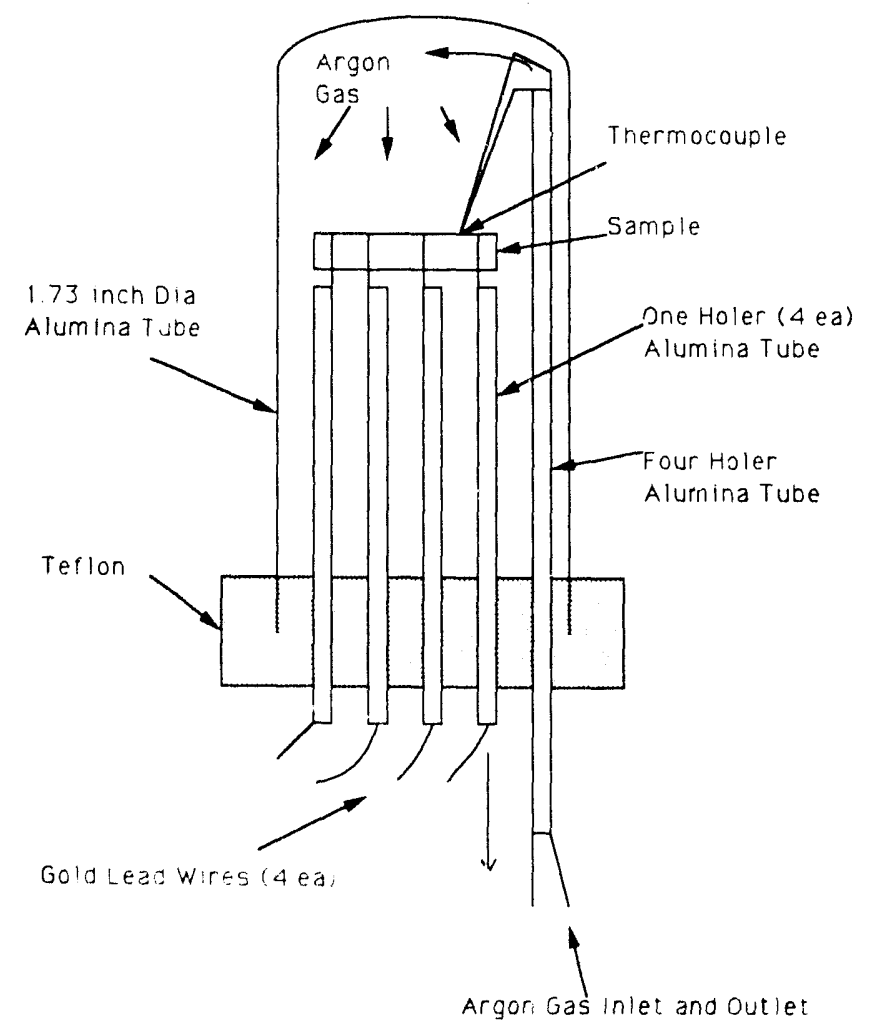

Fig. 7.

Schematic diagram of setup used to measure electrical conductivity 

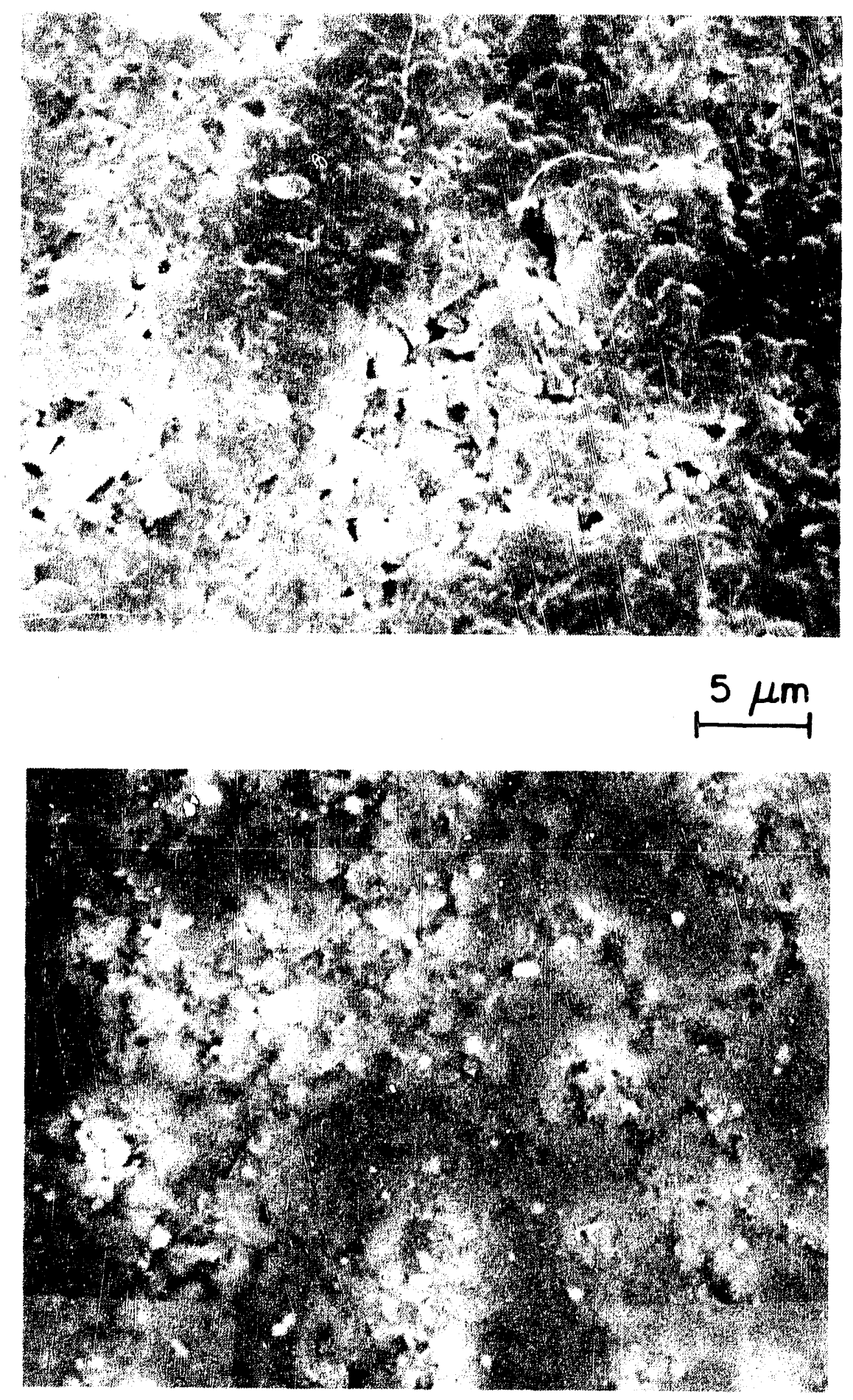

Fig. 8. SEM micrographs of boron nitride (top) and silicon nitride (bottom) samples before exposure to potassium 


\section{Surface Analysis}

Figure 9 shows macroscopic views of the potassium-exposed specimens. Visual examination showed a number of cracks in the boron nitride samples exposed under all conditions. The silicon nitride samples were relatively unaffected. Figures 10 and 11 show SEM microphotographs of boron nitride specimens after exposure at $1400^{\circ} \mathrm{F}$ in potassium vapor and liquid phases, respectively. It is evident that the specimens developed a number of cracks and significant spallation of the material from the surface regions. Energy-dispersive X-ray (EDX) analysis of the surfaces showed substantial amounts of potassium. Figures 12 and 13 show SEM photographs of boron nitride samples after exposure at $1000^{\circ} \mathrm{F}$ in potassium vapor and liquid, respectively. Substantial cracking of the specimens can be seen and the surfaces exhibited large amounts of potassium (as in the samples exposed at $\left.1400^{\circ} \mathrm{F}\right)$. Figure 14 shows SEM photographs of the surface of ANL-archive boron nitride after exposure at $1000^{\circ} \mathrm{F}$ in liquid potassium. The corrosion behavior of this specimen was similar to that of the Carborundum-supplied boron nitride, indicating that the potassium attack of this material is its inherent behavior and is independent of material source.
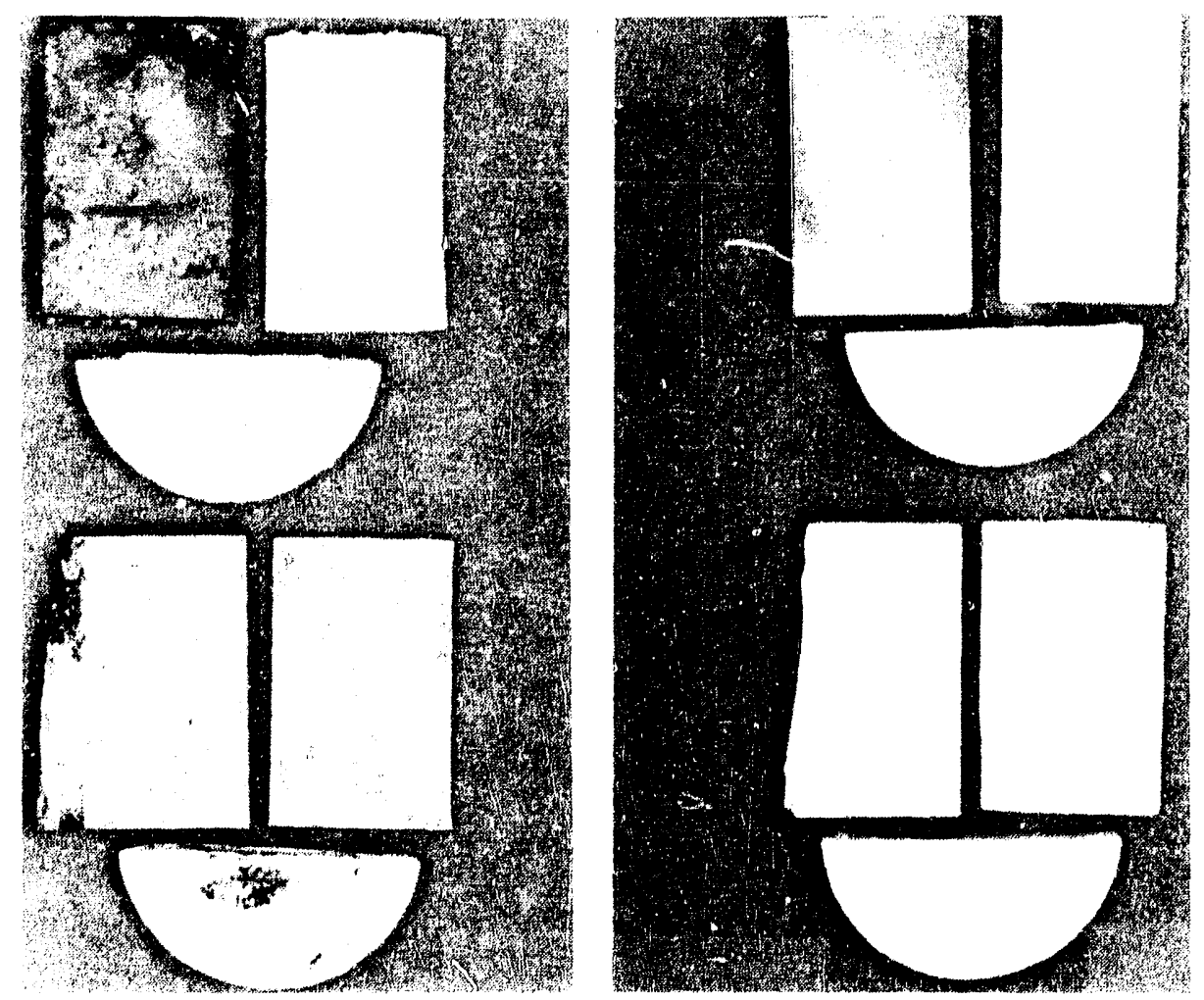

Fig. 9. Macroscopic view of potassium-exposed specimens; exposed at $1000^{\circ} \mathrm{F}$ (left) and $1400^{\circ} \mathrm{F}$ (right); to potassium vapor (top image in each pair) and liquid (bottom image in each pair) 

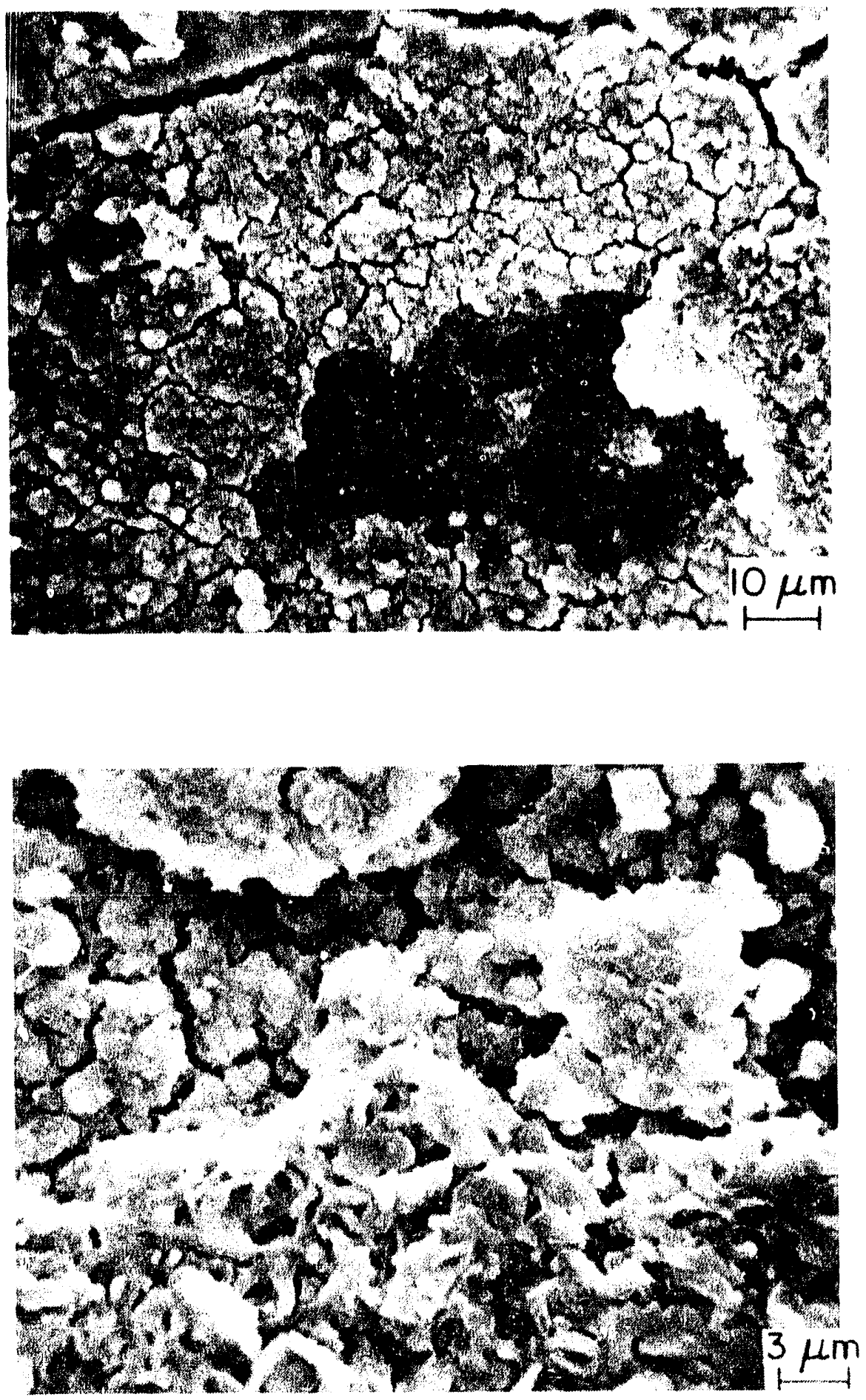

Fig. 10. SEM micrographs of boron nitride specimen after exposure at $1400^{\circ} \mathrm{F}$ in potassium vapor 

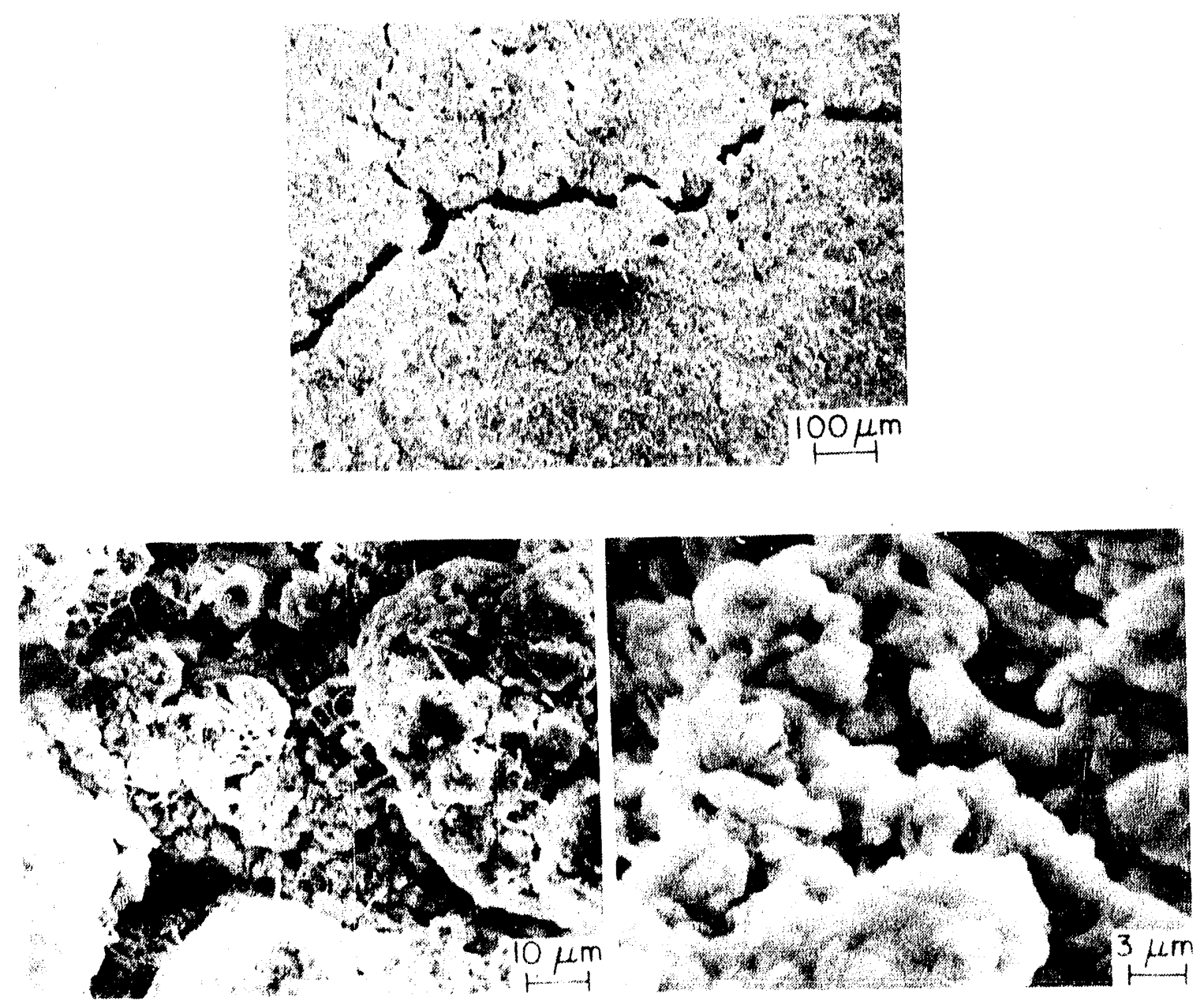

Fig. 11. SEM micrographs of boron nitride specimen after exposure at $1400^{\circ} \mathrm{F}$ in potassium liquid

Figure 15 shows SEM photographs of silicon nitride specimens after exposure at $1400^{\circ} \mathrm{F}$ in vapor and liquid potassium. Potassium was seen in isolated areas on the surface of the specimens but no cracks were observed, indicating the better resistance of this material to potassium attack. This is much more evident in the samples exposed at $1000^{\circ} \mathrm{F}$ (see Fig. 16) in the vapor and liquid phases. Globules of potassium were confined to the surface of the specimens, and the silicon nitride material beneath the material was barely attacked.

\section{Analysis of Cross Sections}

Figures 17 and 18 show SEM micrographs of cross sections of boron nitride samples after exposure at $1000^{\circ} \mathrm{F}$ in potassium vapor and liquid, respectively. Also shown in the figures are the $\mathrm{X}$-ray mapping for potassium. The lighter regions in the mapping photographs represent a high concentration of potassium. It is evident from these figures that potassium has 

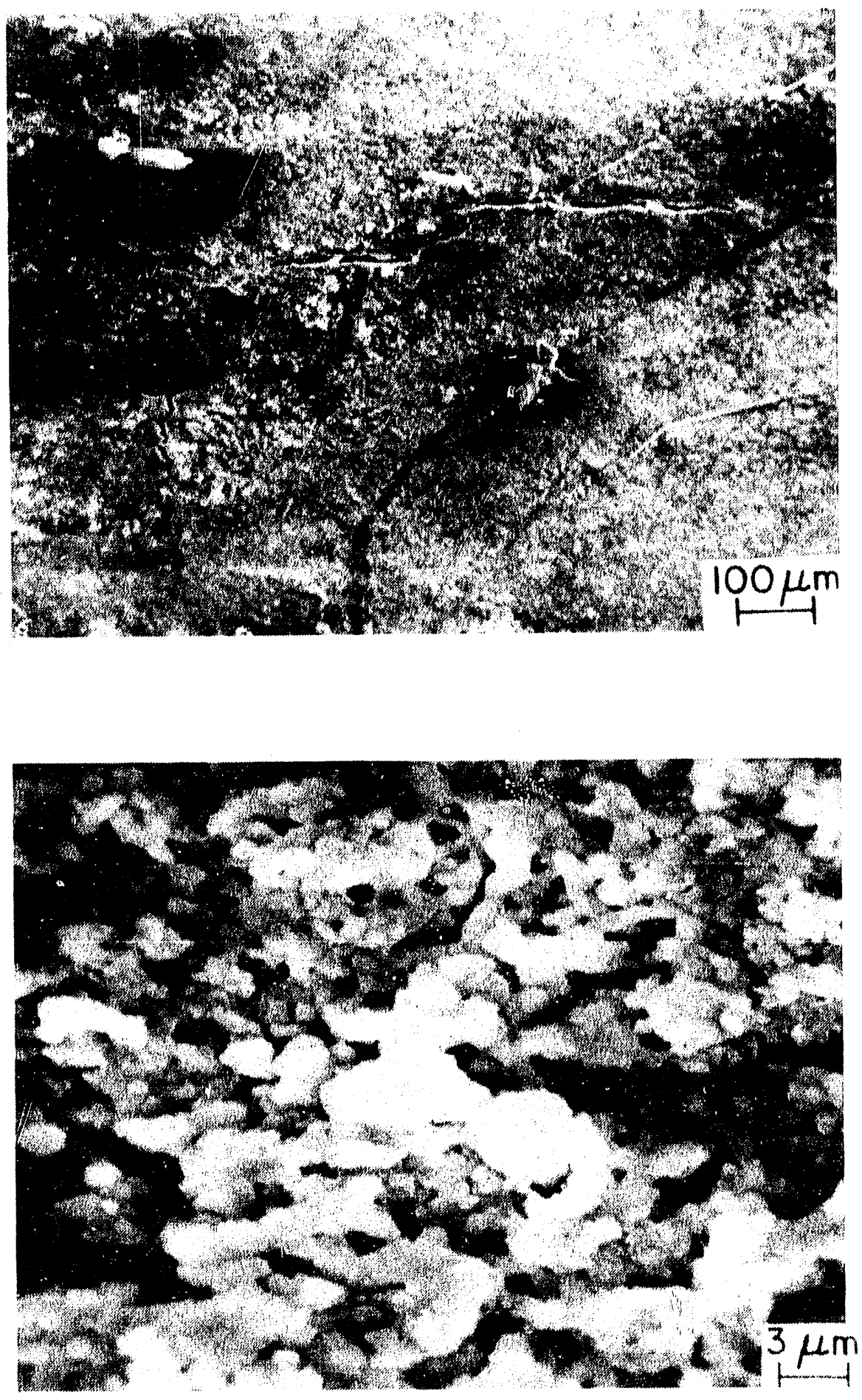

Fig. 12. SEM micrographs of boron nitride specimen after exposure at $1000^{\circ} \mathrm{F}$ in potassium vapor 

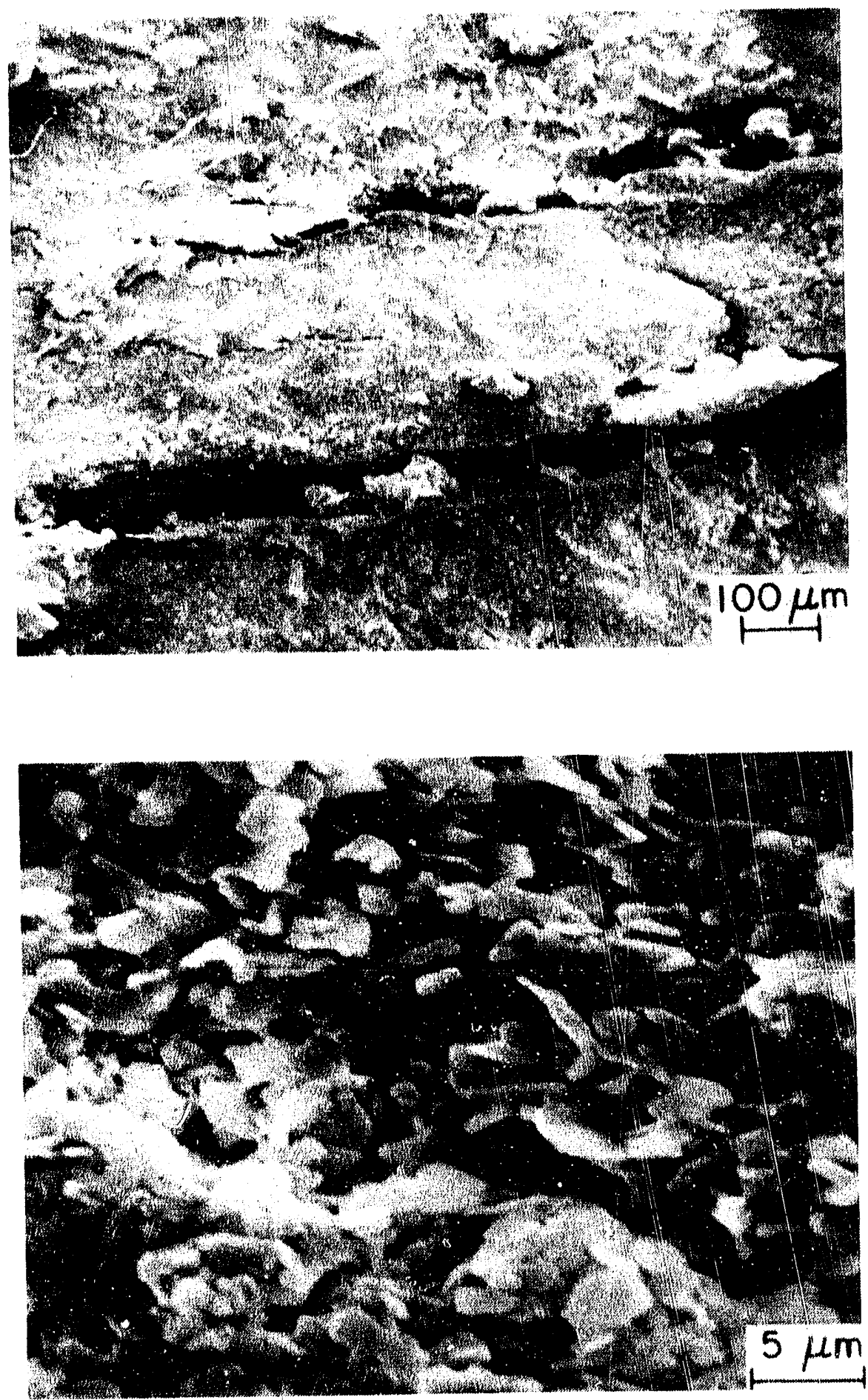

Fig. 13. SEM micrographs of boron nitride specimen after exposure at $1000^{\circ} \mathrm{F}$ in potassium liquid 

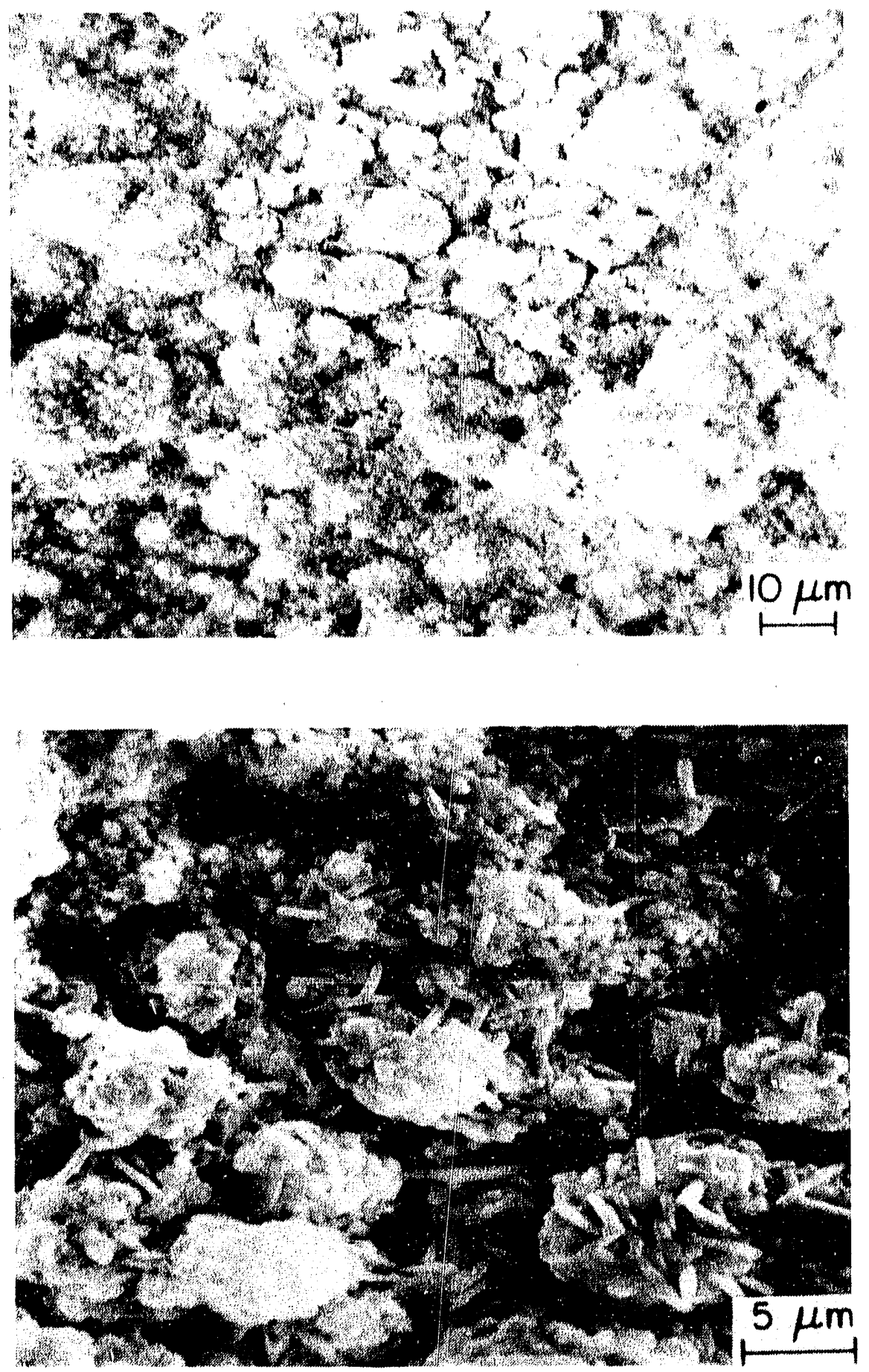

Fig. 14. SEM micrographs of ANL-archive boron nitride specimen after exposure at $1000^{\circ} \mathrm{F}$ in potassium liquid 

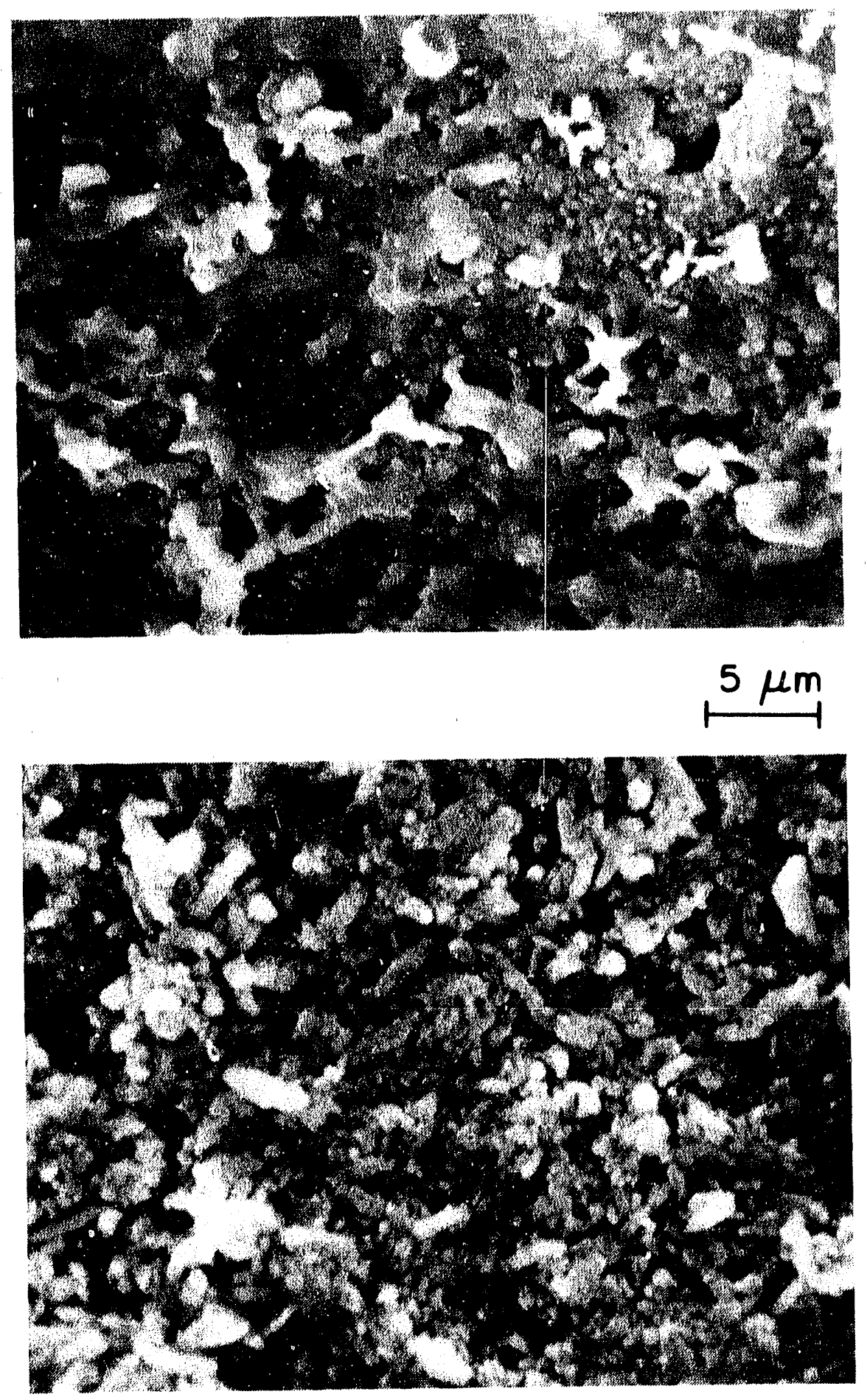

Fig. 15. SEM micrographs of silicon nitride specimens after exposure at $1400^{\circ} \mathrm{F}$ in potassium vapor (top) and liquid (bottom) 

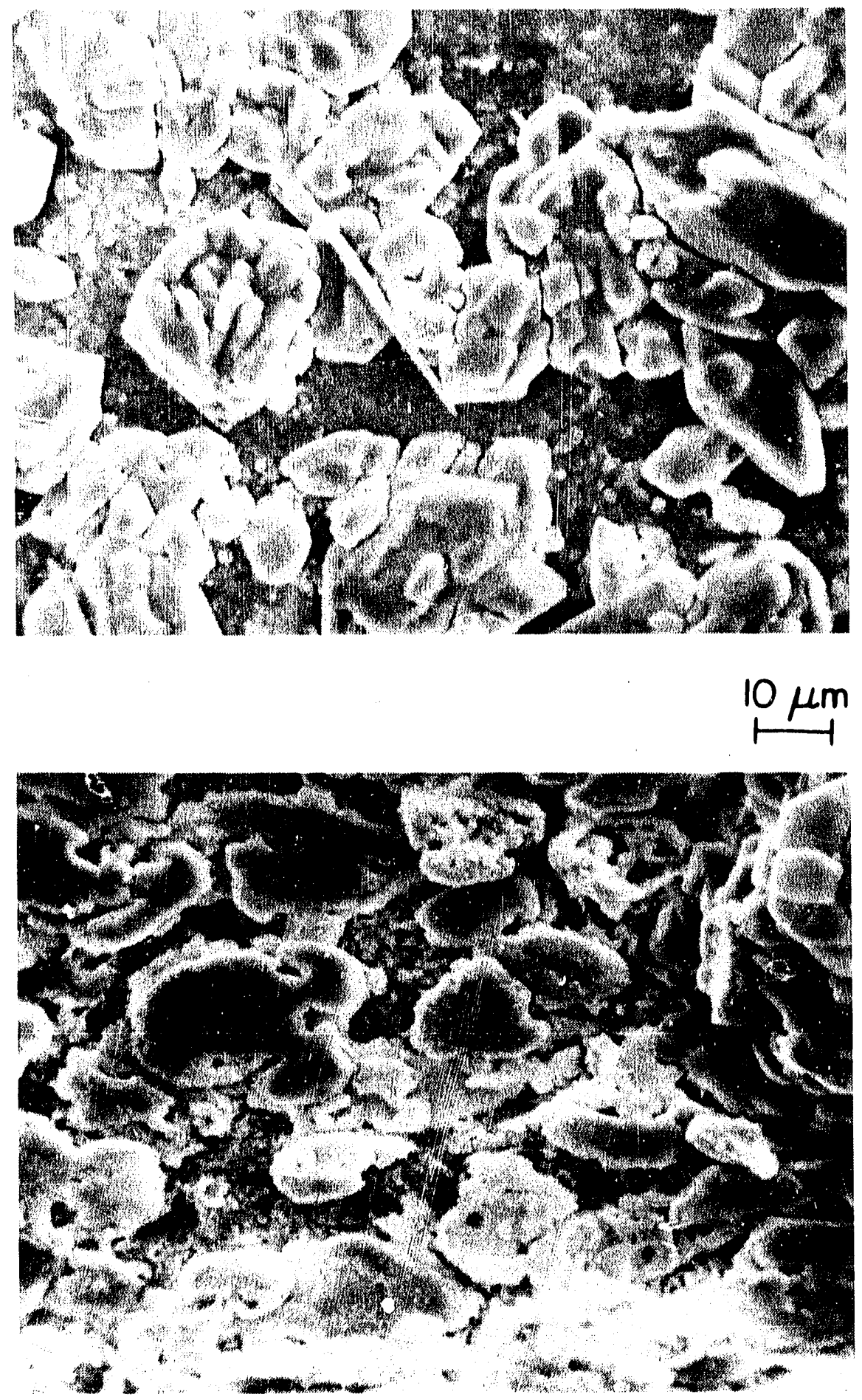

Fig. 16. SEM micrographs of silicon nitride specimens after exposure at $1000^{\circ} \mathrm{F}$ in potassium vapor (top) and liquid (bottom) 

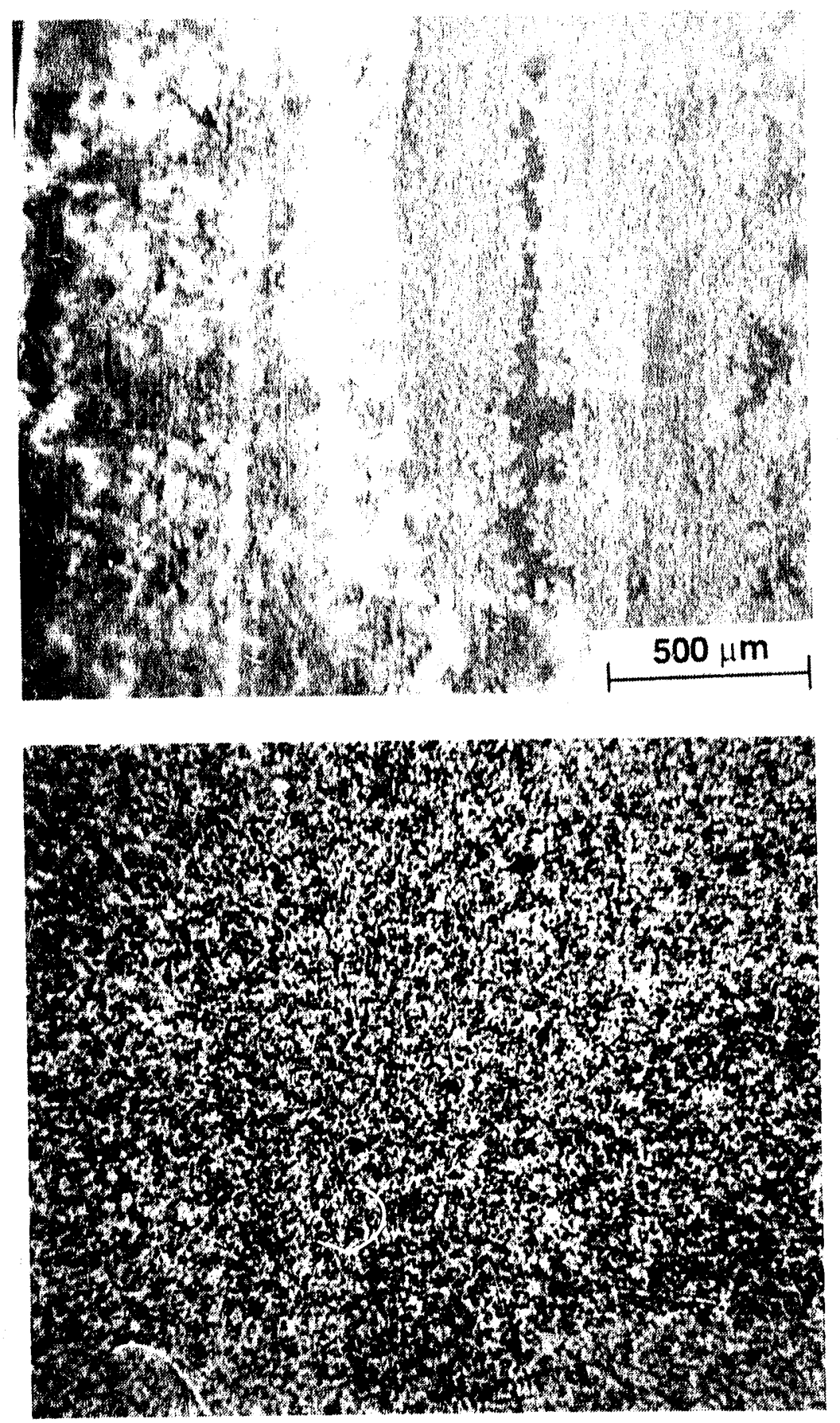

Fig. 17. SEM micrograph and potassium mapping of cross section of boron nitride specimen after exposure at $1000^{\circ} \mathrm{F}$ in potassium vapor 

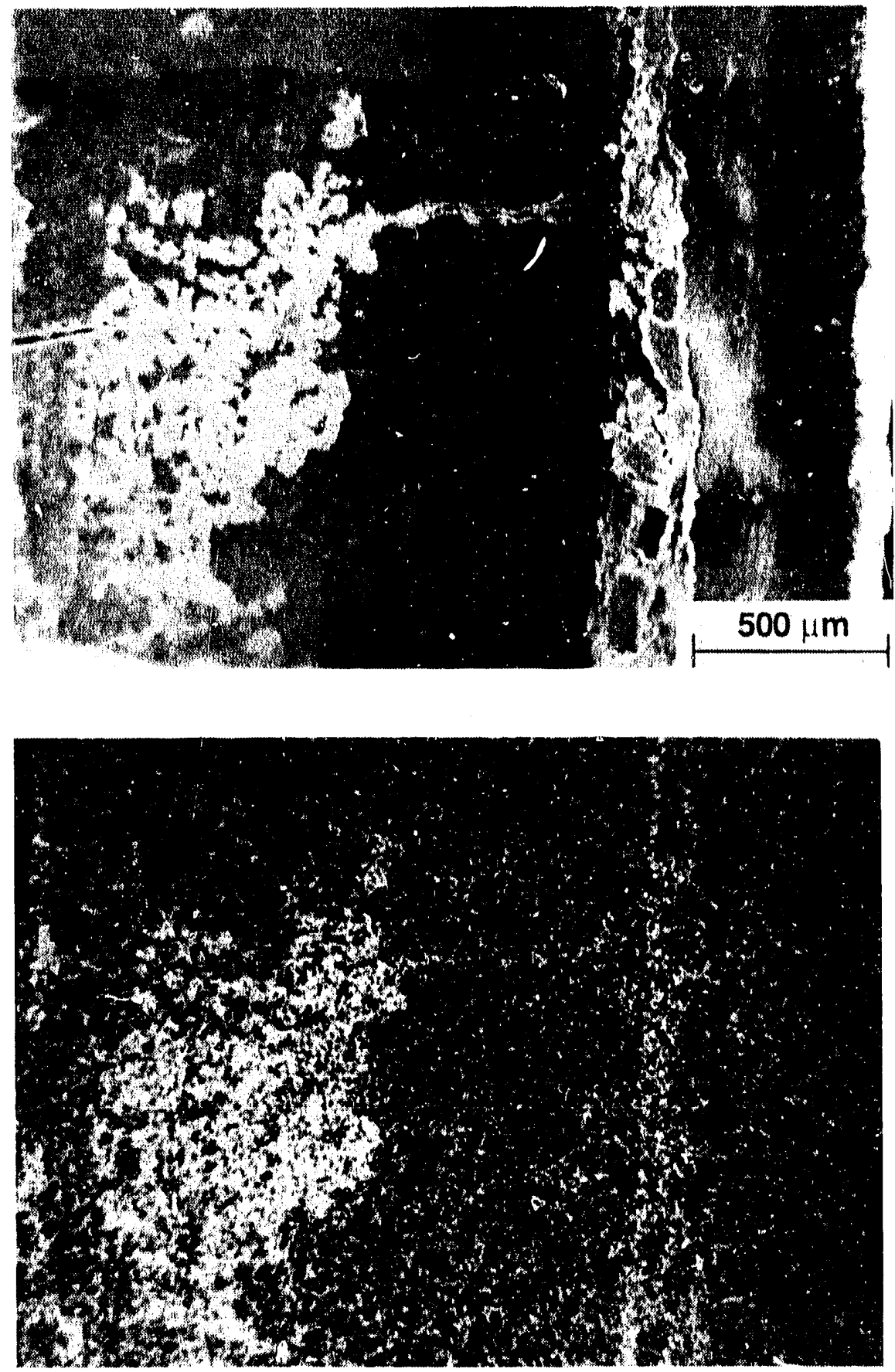

Fig. 18. SEM micrograph and poiassium mapping of cross section of boron nitride specimen after exposure at $1000^{\circ} \mathrm{F}$ in potassium liquid 
penetrated the boron nitride samples throughout their entire cross sections. The exposed samples were very fragile and disintegrated even with a light touch.

The boron nitride specimens exposed to potassium at $1400^{\circ} \mathrm{F}$ falled catastrophically, primarily due to potassium impregnation of the specimens and associated swelling of the specimens. A substantial number of cracks were detected, making it difficult to handle the specimens and to examine them by SEM. Figure 19 shows an SEM photograph and potassium mapping of the cross section of the sample after exposure at $1400^{\circ} \mathrm{F}$ in potassium vapor.

The silicon nitride samples exposed at both temperatures and in vapor and liquid potassium exhibited very little degradation. In fact, because the materials are mechanically strong, they could not be cut and had to be broken with a hammer to examine their cross sections. Figure 20 shows the cross section of a silicon nitride sample after exposure at $1400^{\circ} \mathrm{F}$ in potassium vapor. Even though surfaces of the silicon nitride samples showed evidence of potassium (see earlier figures on surface analyses), none was detected in their cross sections.

\section{Electrical Conductivity Data}

Figures 21 and 22 show conductivity values as a function of temperature for boron nitride specimens before and after exposure at $1400^{\circ} \mathrm{F}$ and $1000^{\circ} \mathrm{F}$, respectively, to potassium vapor and liquid. The conductivity values of the as-fabricated boron nitride are reported (by suppliers) as in the range $10^{-13}$ to $10^{-15}(\mathrm{ohm}-\mathrm{cm})^{-1}$ at room temperature. The measured values for the present material (see data for unexposed boron nitride in Figs. 21 and 22) agree with the vendor-specified values. It was shown eariler that exposure of these materials to potassium vapor or liquid results in significant penetration of potassium into the material. Potassium penetration increases the conductivity (or decreases the resistivity) of the materials by 3 to 7 orders of magnitude after exposure at $1400^{\circ} \mathrm{F}$. The increase in conductivity values for $1000^{\circ} \mathrm{F}$-exposed material is in the range of 2 to 4 orders of magnitude. Note that the exposures were conducted in a static mode in capsules and with a stagnant liquid boundary layer on the specimens immersed in the liquid phase. In the MHD channel, the initial condensation of potassium from the plasma will be via vapor that will accumulate and be present as liquid when the slag constituents deposit and become frozen. However, the boron nitride specimens impregnated with potassium have poor mechanical integrity. 

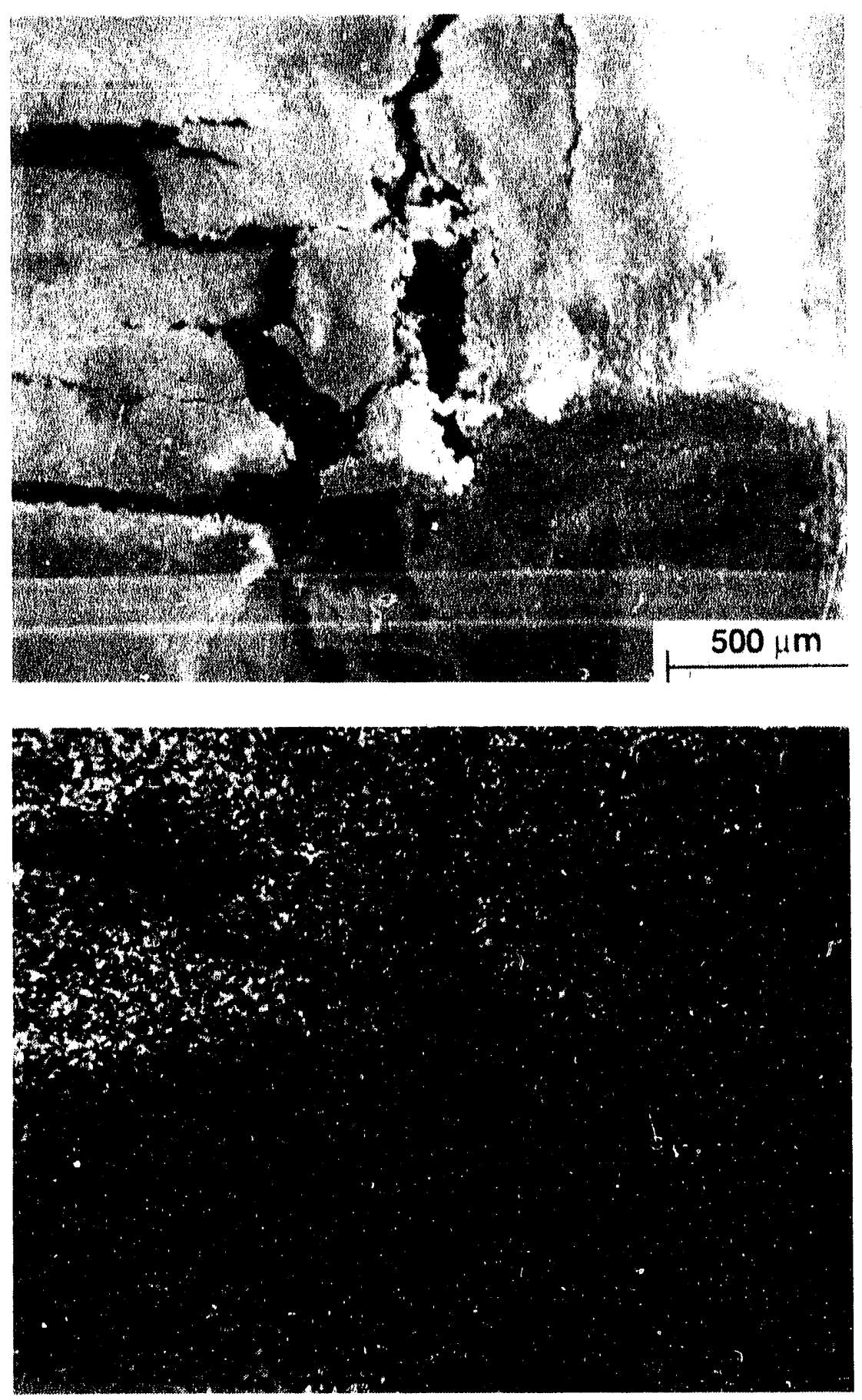

Fig. 19. SEM micrograph and potassium mapping of cross section of boron nitride specimen after exposure at $1400^{\circ} \mathrm{F}$ in potassium vapor 


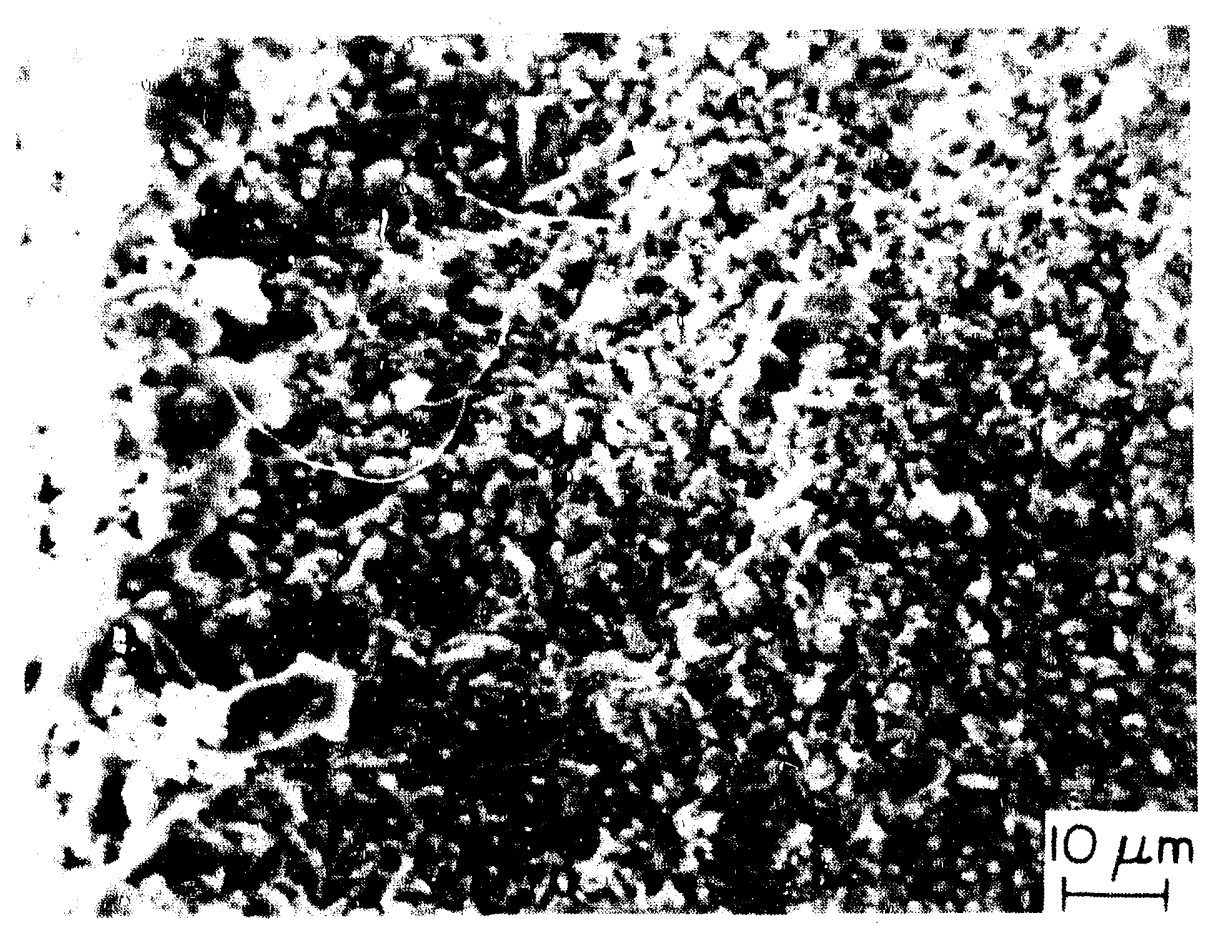

Fig. 20. SEM micrograph of cross section of silicon nitride specimen after exposure at $1400^{\circ} \mathrm{F}$ in potassium vapor

In the silicon nitride specimens, exposure to potassium (either vapor or liquid) had very little effect on electrical conductivity, as shown in Figs. 23 and 24. The conductivity values for unexposed silicon nitride are essentially similar to those ror unexposed boron nitride, especially at temperatures above $\approx 1100^{\circ} \mathrm{F}$. The effect of potassium exposure resulted in at most a 1 -order of magnitude increase in conductivity. In fact, there is virtually no change in conductivity for silicon nitride specimens exposed to potassium at $1000^{\circ} \mathrm{F}$, indicating that adsorption and penetration of potassium into this material is very minimal. This is consistent with the microstructural observations presented above.

\section{IMPLICATIONS FOR MHD CHANNEL DESIGN}

Reliable performance of an MHD channel is strongly dependent on adequate behavior of functional components such as electrodes, insulators, sidebars, etc. This requires chemical compatibility in the hostile MHD environment, mechanical integrity, and acceptable electrical properties.

From the standpoint of chemical compatibility, the boron nitride sample exhibited substantial degradation upon exposure to a potassium environment. The alkali metal penetrated almost the entire thickness at 


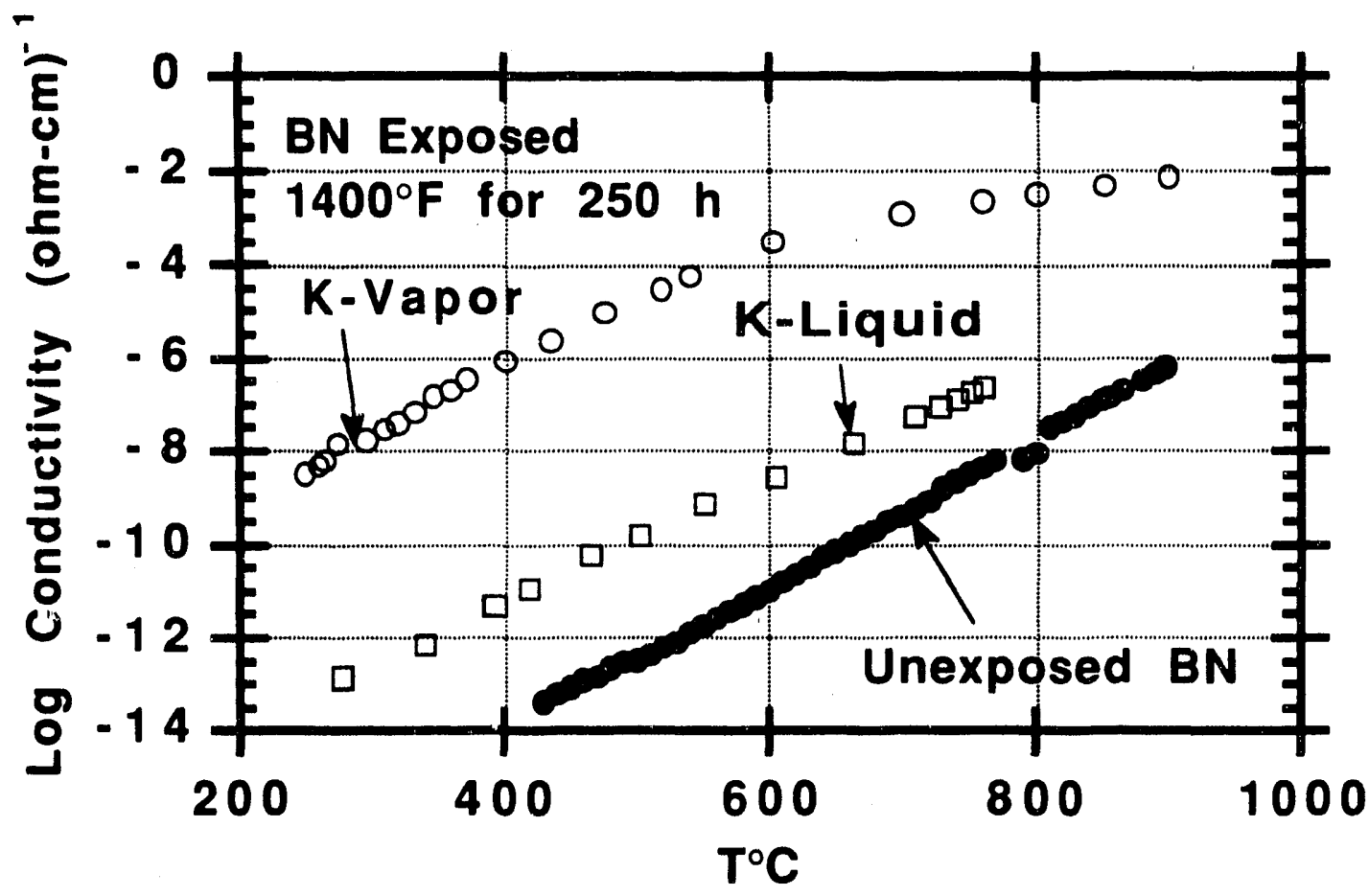

Fig. 21. Electrical conductivity as a function of temperature in boron nitride before and after exposure to potassium vapor or liquid at $1400^{\circ} \mathrm{F}$

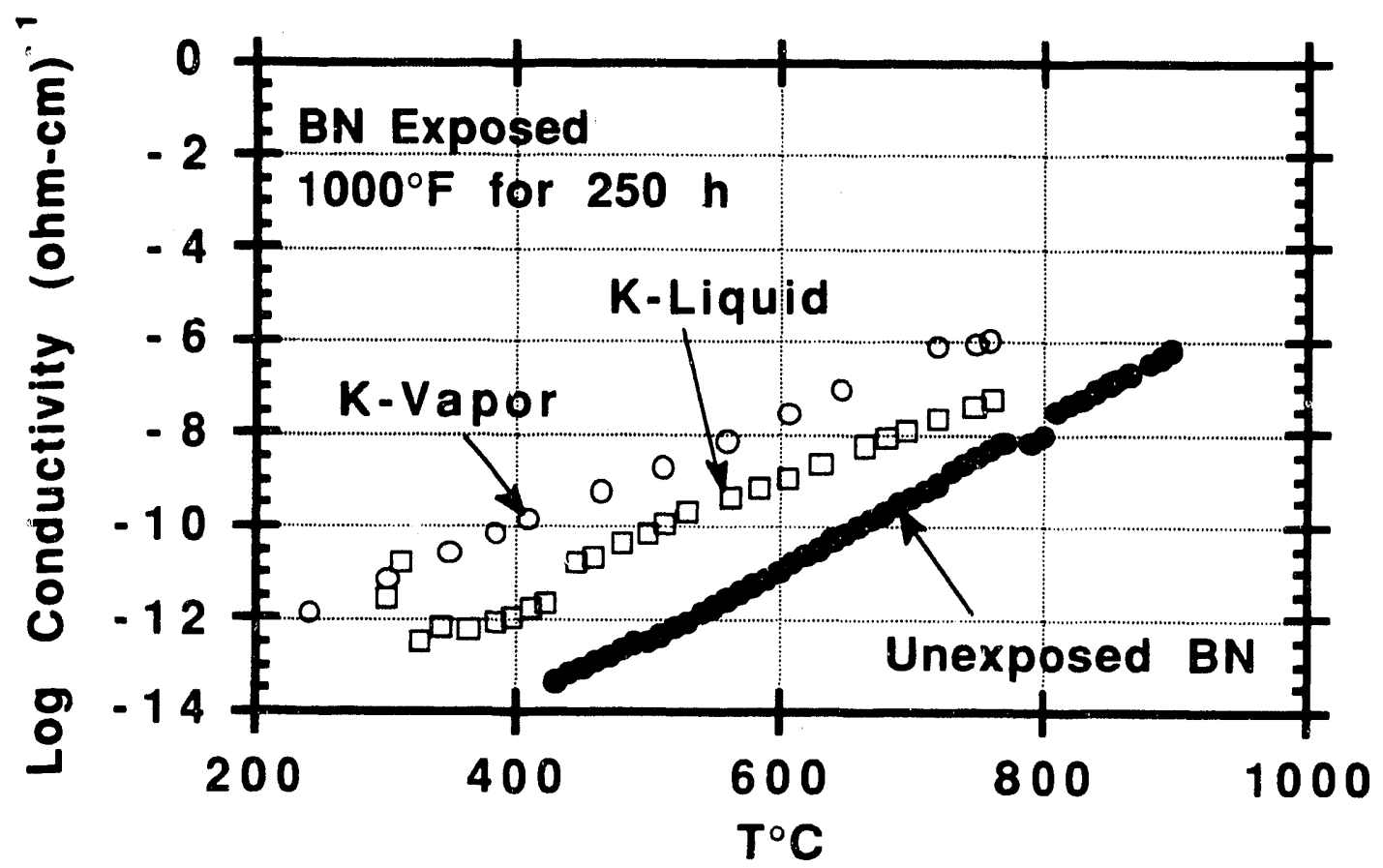

Fig. 22. Electrical conductivity as a function of temperature in boron nitride before and after exposure to potassium vapor or liquid at $1000^{\circ} \mathrm{F}$ 


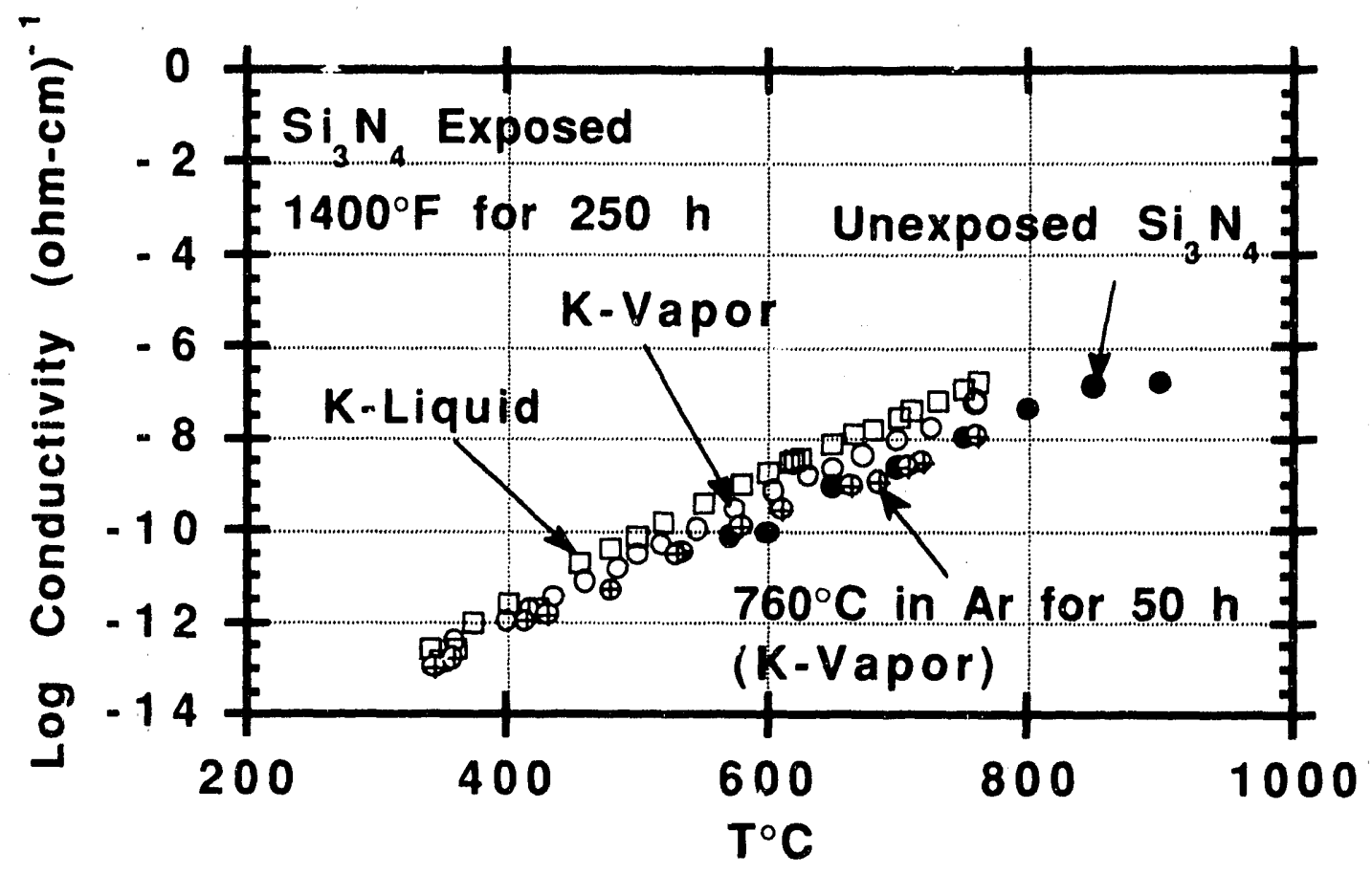

Fig. 23. Electrical conductivity as a function of temperature in silicon nitride before and after exposure to potassium vapor or liquid at $1400^{\circ} \mathrm{F}$

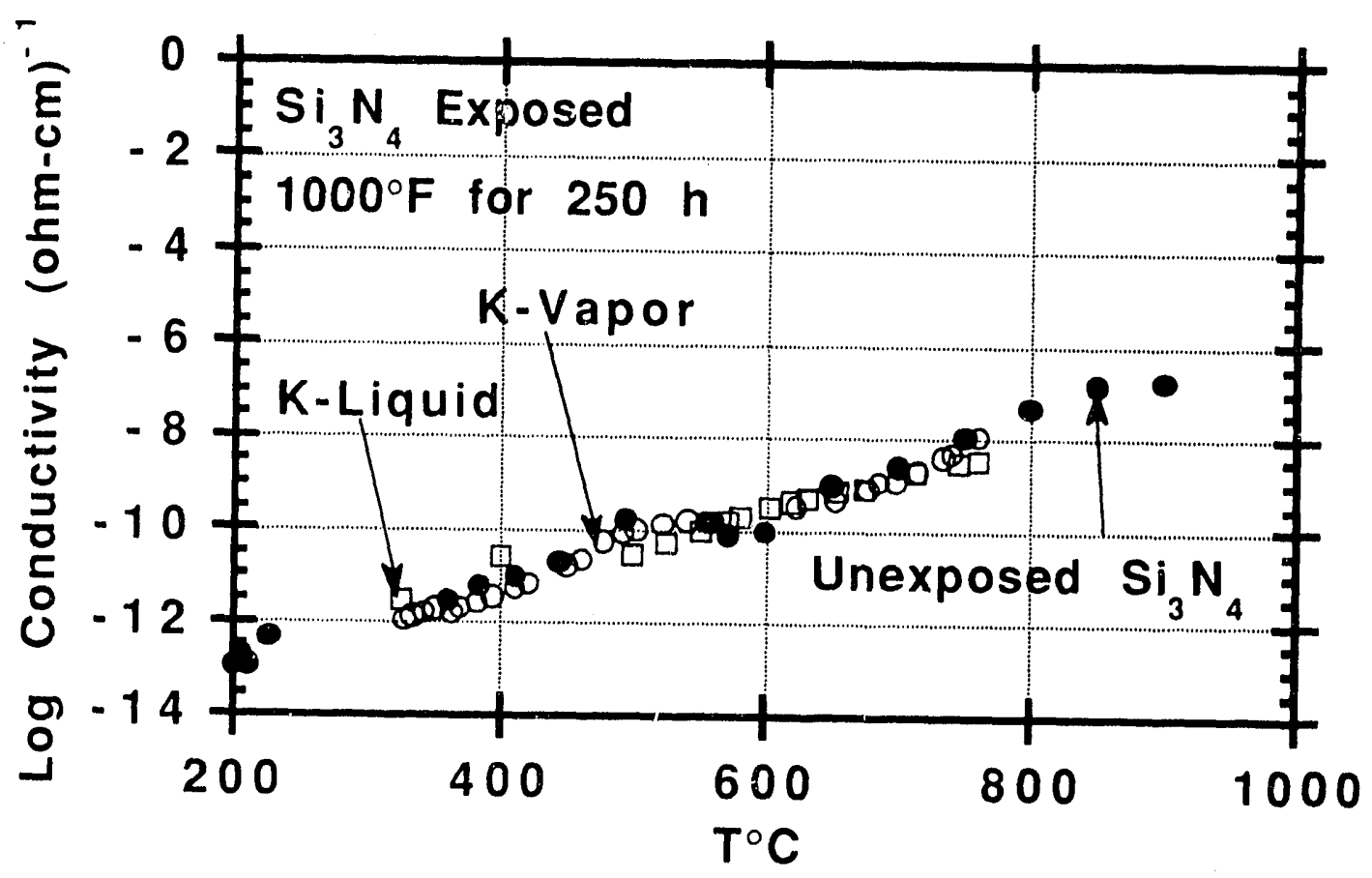

Fig. 24. Electrical conductivity as a function of temperature in silicon nitride before and after exposure to potassium vapor or liquid at $1000^{\circ} \mathrm{F}$ 
$1000^{\circ} \mathrm{F}$, and the sample was virtually destricyed at $1400^{\circ} \mathrm{F}$ by cracking and swelling/spallation. On the other hand, silicen nitride specimens exhibited virtually no attack in a potassium environment. While the hexagonalstructure boron nitride (used in this study) is easily machinable and can be custom-fitted between the electrodes, the silicon nitride is difficult to cut and may not be amenable to a close fit between electrodes.

From the mechanical-integrity standpoint, the potassium-impregnated boron nitride exhibited significant swelling and cracking and lost almost all of its strength. This occurs even after $1000^{\circ} \mathrm{F}$ exposure but more so after $1400^{\circ} \mathrm{F}$. The silicon nitride was virtually unaffected by potassium exposure, as evidenced by the difficulty in cutting of the unexposed and exposed samples for conductivity measurements.

From the standpoint of electrical conductivity, the boron nitride samples exhibited a substantial increase in conductivity (decrease in resistivity) after potassium exposure, especially after $1400^{\circ} \mathrm{F}$. The values obtained for the specimen exposed at $1400^{\circ} \mathrm{F}$ in potassium vapor are high enough to consider this material a noninsulator. It is true that only hexagonal-structure boron nitride (the candidate selected for the prototypical MHD channel) was tested in this study. No testing was conducted on cubic boron nitride. On the other hand, the electrical conductivity values for the silicon nitride specimens were similar to those of boron nitride in the as-fabricated form. Further, exposure to potassium vapor or liquid did not alter the conductivity of the silicon nitride.

On the basis of this study, it may be advantageous to replace boron nitride with silicon nitride as the insulating material in the MHD channel. This could lead to better reliability for the insulating material with regard to chennical compatibility, mechanical integrity, and electrical properties. However, the problem of the hardness of silicon nitride in regard to channel assembly would have to be resolved.

\section{ACBNOWLEDGMENTS}

This work was sponsored by the U.S. Department of Energy, Pittsburgh Energy Technology Center, under Contract W-31-109-Eng-38. 


\section{REFERENCES}

1. L. C. Farrar, Coal-Fired $1 A_{1}$ Channel Gas-Side Element Design and Materials Test Results from the CDIF, Proc. 28th Symp. on Engineering Aspects of Magnetohydrodynamics, eds. G. F. Berry and F. C. Bennett, Jr., June 26-28, 1990, Chicago, p. VI.3-1.

2. E. W. Schmitt, A. W. McClaine, C. C. P. Pian, and L. C. Farrar, Engineering Design and Performance Calculations for a $50 \mathrm{MWt}$ Coal-Fired MHD Generator, ibid, p. VI.5-1. 


\section{Distribution for ANL/MrD-91/1}

\section{Internal}
S. A. Borys
J. H. Park
C. E. Till
H. Drucker
D. L. Rink
T. F. Kassner
D. K. Schmalzer
R. W. Weeks
C. A. Malefyt (2)
W. J. Shack
K. Natesan (10)
M. J. Steindler
P. A. Nelson
W. M. Swift
ANL Patent Dept.
ANL Contract Files
TIS Files (3)

\section{External}

DOE-OSTI, for distribution per UC-1 12 (61)

ANL Libraries

DOE Chicago Operations Office:

D. T. Goldman

F. Herbaty

J. Mavec

Materials and Components Technology Division Review Committee:

H. Berger, Industrial Quality, Inc., Gaithersburg, MD

M. S. Dresselhaus, Massachusetts Institute of Technology, Cambridge, MA

S. J. Green, Electric Power Research Institute, Palo Alto, CA

R. A. Greenkorn, Purdue University, West Lafayette, IN

C. Y. Li, Cornell University, Ithaca, NY

P. G. Shewmon, Ohio State University, Columbus

R. E. Smith, Electric Power Research Institute, NDE Center, Charlotte, NC

Other Government - University - Industry:

L. Angelo, Electric Power Research Institute, Palo Alto, CA

J. L. Bates, Battelle Pacific Northwest Laboratory, Richland, WA

M. Bauer, TRW, Redondo Beach, CA

S. Biondo, Advanced Conversion Division, DOE, Gerniantown, MD

R. Carrabetta, Pittsburgh Energy Technology Center, DOE, Pittsburgh, PA

H. Chambers, Pittsburgh Energy Technology Center, DOE, Pittsburgh, PA

A. Cohn, Electric Power Research Institute, Palo Alto, CA

R. Cook, Mississippi State University, Mississippi State, MS

S. C. Datsko, Babcock \& Wilcox, Alliance, $\mathrm{OH}$

A. Dawson, Massachusetts Institute of Technology, Cambridge, MA 
A. G. Dolbec, Electric Power Research Institute, Palo Alto, CA

F. Hals, AVCO Everett Research Lab., Inc., Everett, MA

E. E. Hoffman, DOE, Oak Ridge Operations Office, Oak Ridge, TN

R. Holman, Westinghouse Electric Corporation, Pittsburgh, PA

N. Joharisoin, University of Tennessee Space Institute, Tullahoma, TN

A. Jones, Westinghouse Electric Corporation, Pittsburgh, PA

R. R. Judkins, Oak Ridge National Laboratory, Oak Ridge, TN

R. Kessler, AVCO Everett Research Lab., Inc., Everett, MA

G. Listvinsky, TRW, Redondo Beach, CA

A. M. Manaker, TVA, Chattanooga, TN

W. Owens, Gilbert Associates, Inc., Gaithersburg, MD

G. Parker, Westinghouse Electric Corporation, Pittsburgh, PA

S. Petty, AVCO Ererett Research Laboratory, Inc., Everett, MA

R. Rhodenizer, General Electric Company, Schenectady, NY

R. Rosa, Montana State University, Bozeman, MT

S. J. Schneider, National Institute of Standards and Technology, Gaithersburg, MD

W. S. Shepard, Mississippi State University, Mississippi State, MS

J. Sherrick, Mountain States Energy, Inc., Butte, MT

A. Solbes, TRW, Redondo Beach, CA

G. Staats, Pittsburgh Energy Technology Center, DOE, Pittsburgh, PA

C. Thomas, Pittsburgh Energy Technology Center, DOE, Pittsburgh, PA

G. Vivian, DOE, Butte, MT

B. Zauderer, Coal Tech Corporation, Merion Station, PA 

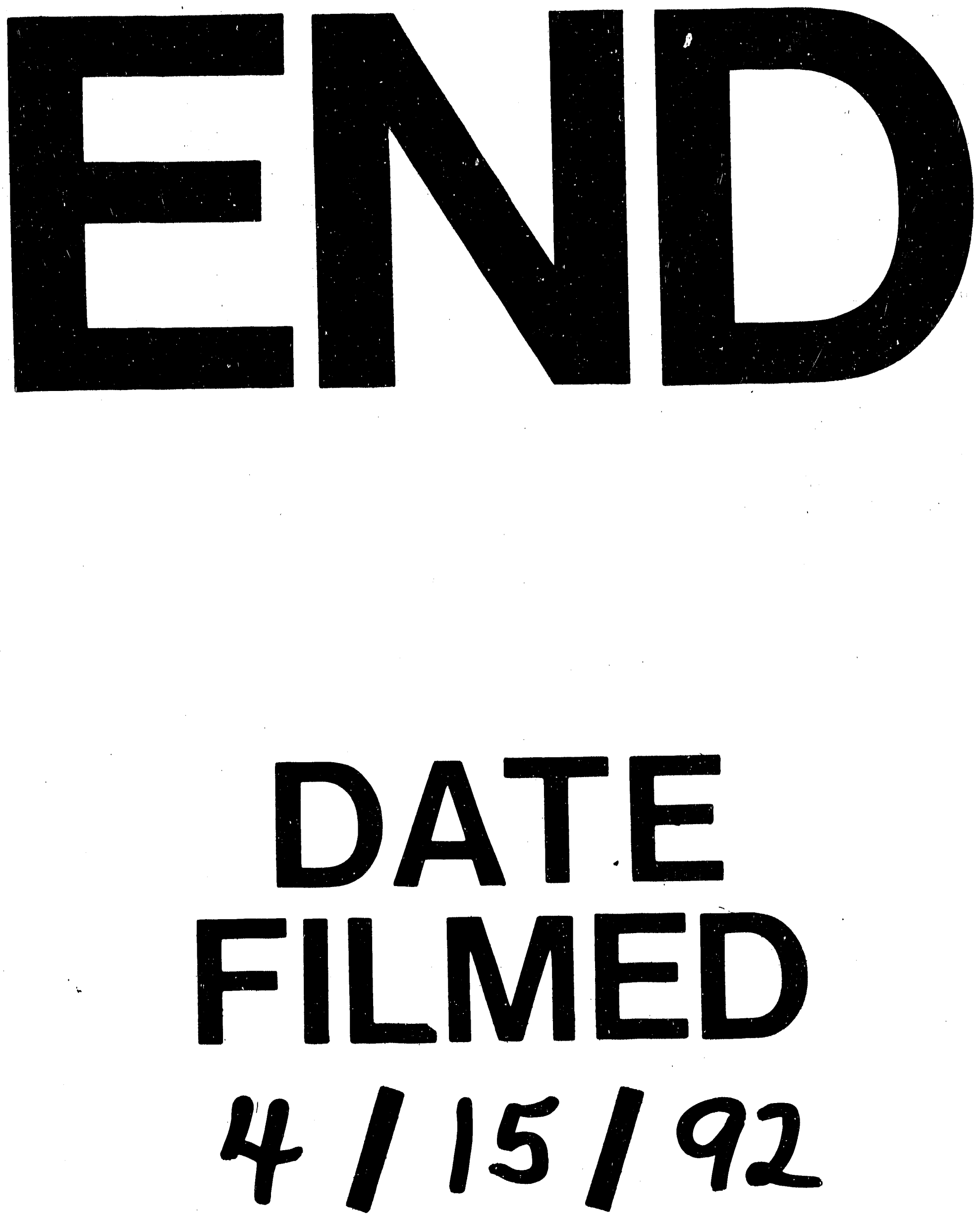
